The Fragmented United States of America: The impact of scattered lock-down policies on country-wide infections Jacek Rothert, Ryan Brady, and Michael Insler 


\title{
The Fragmented United States of America: The impact of scattered lock-down policies on country-wide infections
}

\author{
Jacek Rothert \\ U.S. Naval Academy \\ and FAME|GRAPE
}

\author{
Ryan Brady \\ U.S. Naval Academy
}

Michael Insler

U.S. Naval Academy

\begin{abstract}
Fragmented by policies, united by outcomes: This is the picture of the United States that emerges from our analysis of the spatial diffusion of Covid-19 and the scattered lock-down policies introduced by individual states. We first use spatial econometric techniques to document spillovers of new infections across county and state lines, as well as the impact of individual states' lock-down policies on infections in neighboring states. We find evidence that new cases diffuse across county lines and that the diffusion across counties was affected by the closure policies of adjacent states. Spatial impulse response functions reveal that the diffusion across counties is persistent. We then develop a spatial version of the epidemiological SIR model where new infections arise from interactions between infected people in one state and susceptible people in the same or in neighboring states. We incorporate lock-down policies and calibrate the model to match both the cumulative and the new infections across the 48 contiguous U.S. states and DC. Our results suggest that lax policies in the most lenient states translate into millions of additional infections in the rest of the country. In our spatial SIR model, the spatial containment policies such as border closures have a bigger impact on flattening the infection curve in the short-run than on the cumulative infections in the long-run.
\end{abstract}

Keywords:

diffusion, spatial model, Covid-19, epidemics

JEL Classification

R15, H77, I19

Corresponding author

Jacek Rothert, jacek.rothert@gmail.com

\section{Acknowledgements}

The views expressed here are those of the authors and do not represent the views of the United States Naval Academy, the Department of Defense, or the Federal Government. Jacek Rothert gratefully acknowledges the support of NCN grant \#2019/35/B/HS4/0076. All errors remain ours.

Published by: $\quad$ FAME | GRAPE

ISSN: $\quad$ 2544-2473

(c) with the authors, 2020

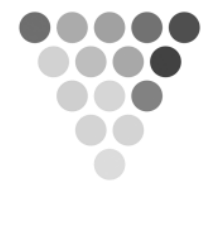




\section{Introduction}

In this paper we assess the spatial diffusion of Covid-19 in the United States and the effect that state-level lock-down policies have on that diffusion. Our analysis is motivated by the idea that, if there were substantial spillovers of new infections between states, then the uncoordinated responses

at the state level may have exacerbated the outbreak of the disease. But, how large those interregion spillovers were, or are, is uncertain - as is the extent to which the relatively lax policies of one state contributed to new infections in surrounding states. Indeed, as is now well-documented, the virus spread quickly throughout the United States, with notable variations in state-level policy to follow. By March 6, a majority of U.S. states had at least one confirmed case of the virus, and by March 17 the last state (West Virginia) reported its first case. While the Center for Disease Control (CDC) and and other federal entities issued guidance on appropriate measures to mitigate the spread of the virus, the final decisions regarding the timing and the extent of restrictions were made by individual states, and sometimes even counties. The first state-wide "shelter-in-place" order was issued in California on March 19, but ultimately only 24 additional states followed suit over the next two weeks. The compliance with social distancing measures also varied greatly across regions (Painter and Qiu, 2020; Simonov et al., 2020). The goal of this paper is to assess the impact of such a scattered policy response on the country-wide spread of the virus.

Our analysis follows a two-pronged approach. First, we employ both spatial econometric and time-series methods to measure the extent of the spatial correlation between regions in the U.S., and to understand the dynamics, or the persistence, of that spatial correlation over time. To that end, we estimate direct and indirect spatial spillovers from a variety of workhorse spatial models. For each model the dependent variable is the simple growth rate of county-level cases, and our primary covariate is a measure of the number of restrictions put in place in the state in which the county resides. We find consistent statistical evidence that not only did new cases diffuse across county lines, holding county level factors constant, but that the spatial diffusion across counties was affected by the closure policies of adjacent states. Next, to measure the temporal dynamics of 
the spatial spillovers we generate "spatial impulse response functions" (IRFs), showing how long a particular county was affected by its neighbors' rate of new cases. We find that the spatial diffusion of new cases is statistically significant and persistent over time, for at least ten days over our forecast horizon. Considered together, our results from the spatial models and IRFs provide an informative picture on the nature of the spatial correlation of the Covid-19 phenomenon. Our empirical results suggest, too, that more stringent state-level restrictions are consistent with a decline in the growth rate of new cases at the county level.

Second, we develop a spatial version of the standard epidemiological SIR (Susceptible-InfectedRecovered) model based on Kermack and McKendrick (1927), which has been popularized in the economics literature by Atkeson (2020b). In our model individuals can be infected by people from their own states and from other states. Those inter-state contacts endogenously create a spatial diffusion of the infections, with the speed of such diffusion depending on the model parameters that measure the relative frequency of connections across state lines, potentially altered by social distancing measures. We calibrate the model parameters by minimizing the distance between the data and the model generated series. We then use the model to simulate the impact of lock-down policies implemented in the states with the most restrictive and most lax policies. ${ }^{1}$ Our main results in that section are twofold. First, if the individual states had the ability to restrict the travel across their borders, infections would be smaller. ${ }^{2}$ Specifically, cutting the value of the calibrated interstate spillover parameter by $25 \%$ results in the reduction of country-wide infections by almost $40 \%$ in the first 3 months, and by almost $7 \%$ in the long-run. Second, if the states with the more lenient lock-down policies tightened them by one level, the cumulative cases in the remaining states would be reduced by $2 \%$ in the first three months, and by more than $5 \%$ over the 21 -month period.

Our analysis contributes to a large and quickly growing literature on the economics of Covid-19. First, we expand the empirical literature that focuses on the spatial aspects of the outbreak. A few studies analyzed drivers of spatial heterogeneity in the scope or severity of the Covid-19 pandemic:

\footnotetext{
${ }^{1}$ We discuss possible limitations arising due to the Lucas' critique in Section 4.3.

${ }^{2}$ Of course, we do not suggest that giving the states such ability would be desirable. We are merely evaluating its potential impact on the spread of infections across the whole country.
} 
Desmet and Wacziarg (2020) and Gerritse (2020) looked at US counties, Verwimp (2020) at Belgian municipalities, and Ginsburgh et al. (2020) at French regions. Very few papers seemed to focus on understanding the geographic spread of the infections. Kuchler et al. (2020) analyze the correlation between the growth in new cases and the degree of social connectedness with the Covid hotspots, using an aggregated data from Facebook. Cuñat and Zymek (2020) analyze geographical spread of the virus in the U.K. by incorporating individual's location and mobility decisions with the SIR model. The most closely related study is Eckardt et al. (2020), where the authors analyze how the border closures slowed down the spread of the virus. Our paper offers the first empirical attempt to estimate the extent of spatial diffusion of Covid-19 in the United States. Our main objective is to quantify the extent of inter-state spillovers and the impact of one state's containment measures on outcomes in surrounding states, with close attention paid both to containment measures and possible non-compliance with them.

Second, our results are important for the discussion of policy coordination. It is quite well known that in the presence of inter-state spillovers, an uncoordinated policy response may lead to sub-optimal outcomes. In the context of Covid-19, the discussion in this area has been mostly theoretical. Beck and Wagner (2020) provide a model of optimal international coordination, focusing on the timing of such coordination. Rothert (2020) uses a heterogeneous agents framework with rich and poor households from Michaud and Rothert (2018) to shows that in the presence of an uncoordinated response, a federal income-based redistribution can flatten the curve if the state governments cannot easily increase welfare spending. Our paper offers the first empirical insight into the actual magnitude of such inter-regional spillovers. Our findings suggest that those spillovers are substantial and therefore emphasize the importance of a coordinated policy response.

Third, the variation in state-level restrictions plays a key role in our analysis. This associates us with a number of papers that focus on the effectiveness of various social distancing measures or on the compliance with the official rules. ${ }^{3}$ Painter and Qiu (2020) and Simonov et al. (2020) show that compliance with social distancing rules in the U.S. is correlated with party affiliation,

\footnotetext{
${ }^{3}$ See e.g., Weber (2020), Pragyan Deb and Tawk (2020), Jinjarak et al. (2020).
} 
and with exposure to certain opinion-forming programs on Fox News. Briscese et al. (2020) show that the compliance can vary over time and that people can become "tired of" restrictions. In our analysis we use a measure of state-imposed restrictions and we also allow for imperfect compliance with them. Our results indicate that stricter social distancing measures introduced by individual states, and better compliance with them, limit the spread of the disease not only within those states, but also in the neighboring states. Conversely, the lack of such restrictions makes it harder for the state's neighbors to contain the virus.

Finally, following Atkeson (2020b), a number of papers have contributed to modelling the spread of the pandemic. The SIR model has become the standard in that literature with different papers suggesting different modifications, depending on the paper's focus. ${ }^{4}$ The closest papers to ours are Bisin and Moro (2020) and Acemoglu et al. (2020). The former builds a theoretical framework that formalizes aspects such as local travel and changes in individuals' behavior, but their focus is on the local diffusion around the hot-spot of the outbreak. The latter develops a multi-group version of the SIR model where infection risks differ across population groups (e.g., nursing homes, schools, etc.) and allows for the transmission of infections between population subgroups. Our main contribution is to develop a spatial version of the benchmark SIR model that allows us to quantify the spillover effects of local infections as well as local lock-down policies on the spread of the virus in other parts of the country.

\section{Covid-19 outbreaks and policy responses across the U.S.}

We start by documenting some stylized facts about the time and spatial dimensions of the spread of Covid-19 and containment measures in the United States.

\subsection{Data}

We utilize three data sources in this paper:

\footnotetext{
${ }^{4}$ A non-exhaustive list of examples includes Atkeson et al. (2020), Holden and Thornton (2020), McAdams (2020), Favero (2020), Berger et al. (2020), Hornstein (2020), or Ellison (2020).
} 
1. Daily county-level data on confirmed cases and deaths are from the Covid-19 Data Repository by the Center for Systems Science and Engineering (CSSE) at Johns Hopkins University (Dong et al. (2020)).

2. Daily state-level data on business closures and mandated social distancing measures are from the Institute for Health Metrics and Evaluation (IHME). Specifically, we utilize IHMEcompiled information on five such metrics including the date on which a state proceeded as follows: forbade mass gatherings, introduced an initial round of business closures, closed schools, closed all non-essential businesses, and adopted a stay-at-home order. For each day in our time series, we sum the number of currently-imposed restrictions within a state to generate a measure of government-imposed behavior restrictions at the state level. This metric is thus a count variable taking values 0 through 5 , which we call $\mathrm{r}$-score.

3. County-level data on socioeconomic, demographic, and geographic characteristics from the Bureau of Economic Analysis (BEA). In the analysis below we incorporate county-level information on population density for the year 2018 (BEA and U.S. Census Bureau), the share of the county-level population over age 60 for the year 2018 (U.S. Census Bureau), and partisan voting share from the 2016 presidential election. ${ }^{5}$

\subsection{Covid-19 cases across time and space}

In this section we conduct some basic visual analysis to demonstrate the extent of the Covid-19 epidemic in the United States. We do so to provide a descriptive look at the dynamics of the inter-state and inter-county spillover of the virus.

Figure 1 displays the spread of Covid-19 across the whole country over time. The blue line plots the proportion of counties with confirmed cases over time, demonstrating the breadth of the epidemic. The red line reveals its depth, displaying how the share of the population living in a county with at least one confirmed case quickly rose from close to zero to close to one during the

\footnotetext{
${ }^{5}$ Via Luis Sevillano on GitHub, but originally published in the New York Times and available here.
} 


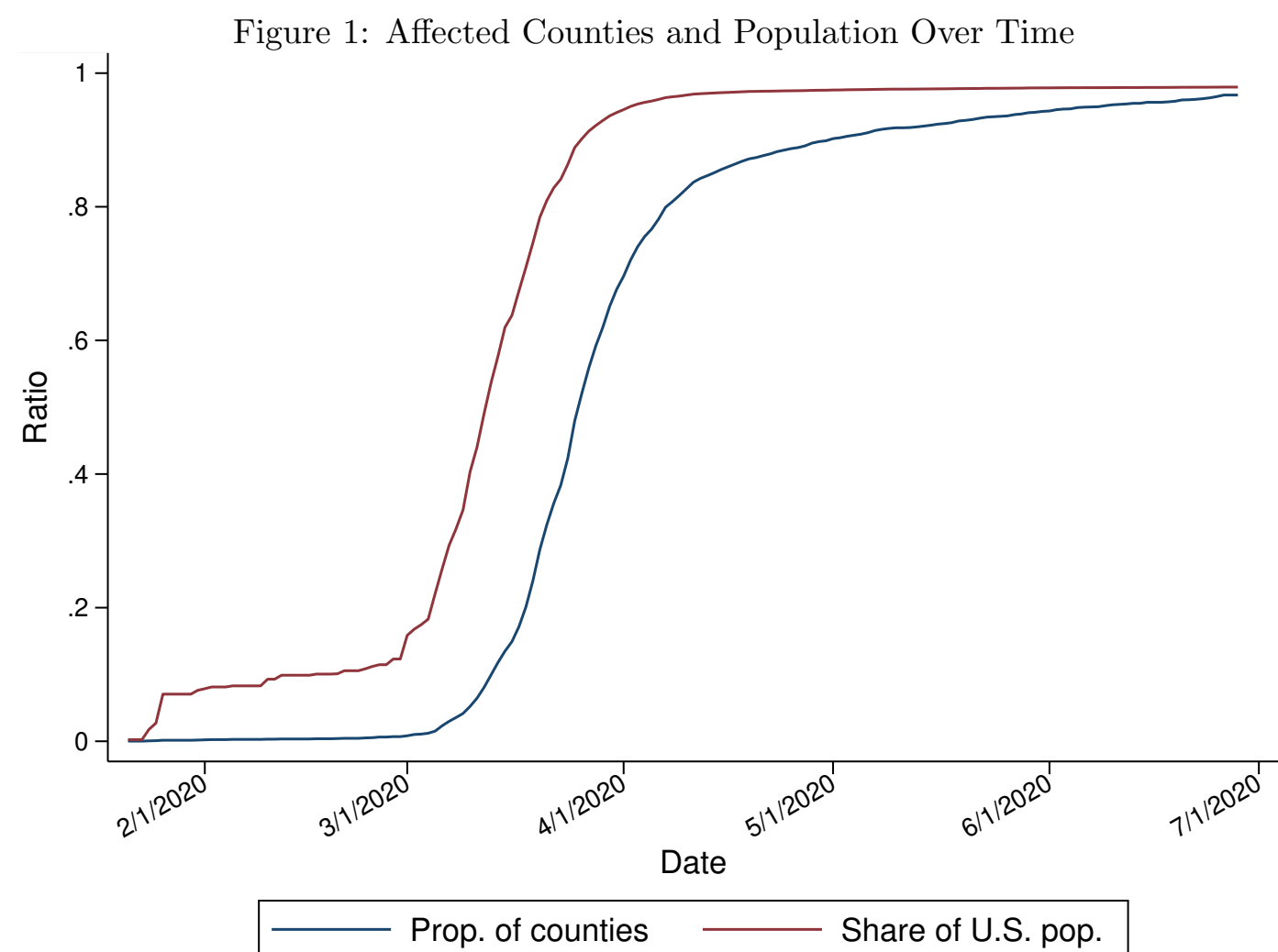

month of March. It is clear that from March through June, Covid-19 transitioned from a fairly sparse outbreak to a widespread epidemic among counties along both the extensive and intensive margins.

New York was the first state in the U.S. to experience a very significant outbreak, with its epicenter in New York City (NYC). A simple inspection of the dynamics of case numbers in and around NYC indicates the importance of interstate spillovers (within the CT-NJ-NY-PA areas). Figure 2 shows a rapid expansion of per-capita case numbers in New York during the second half of March, followed by all other states surrounding the NYC metropolitan area in late March and the first half of April. In the case of New Jersey, per-capita case counts caught up to-and began to outpace - those of New York in mid-April.

Closer inspection at the county level in other metropolitan areas reveals similar patterns. Figure 


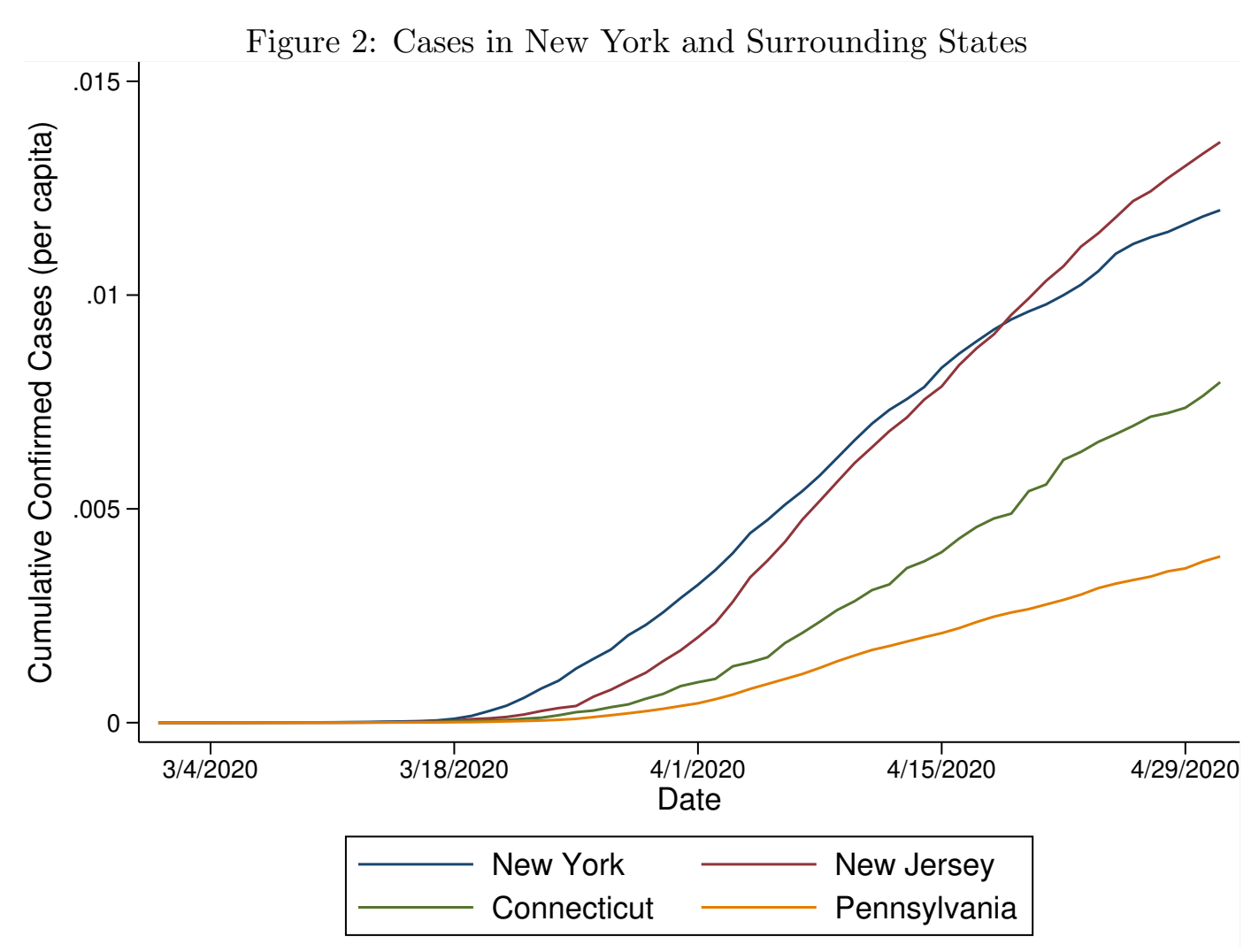


Figure 3: County-level Cases in Major Metropolitan Areas
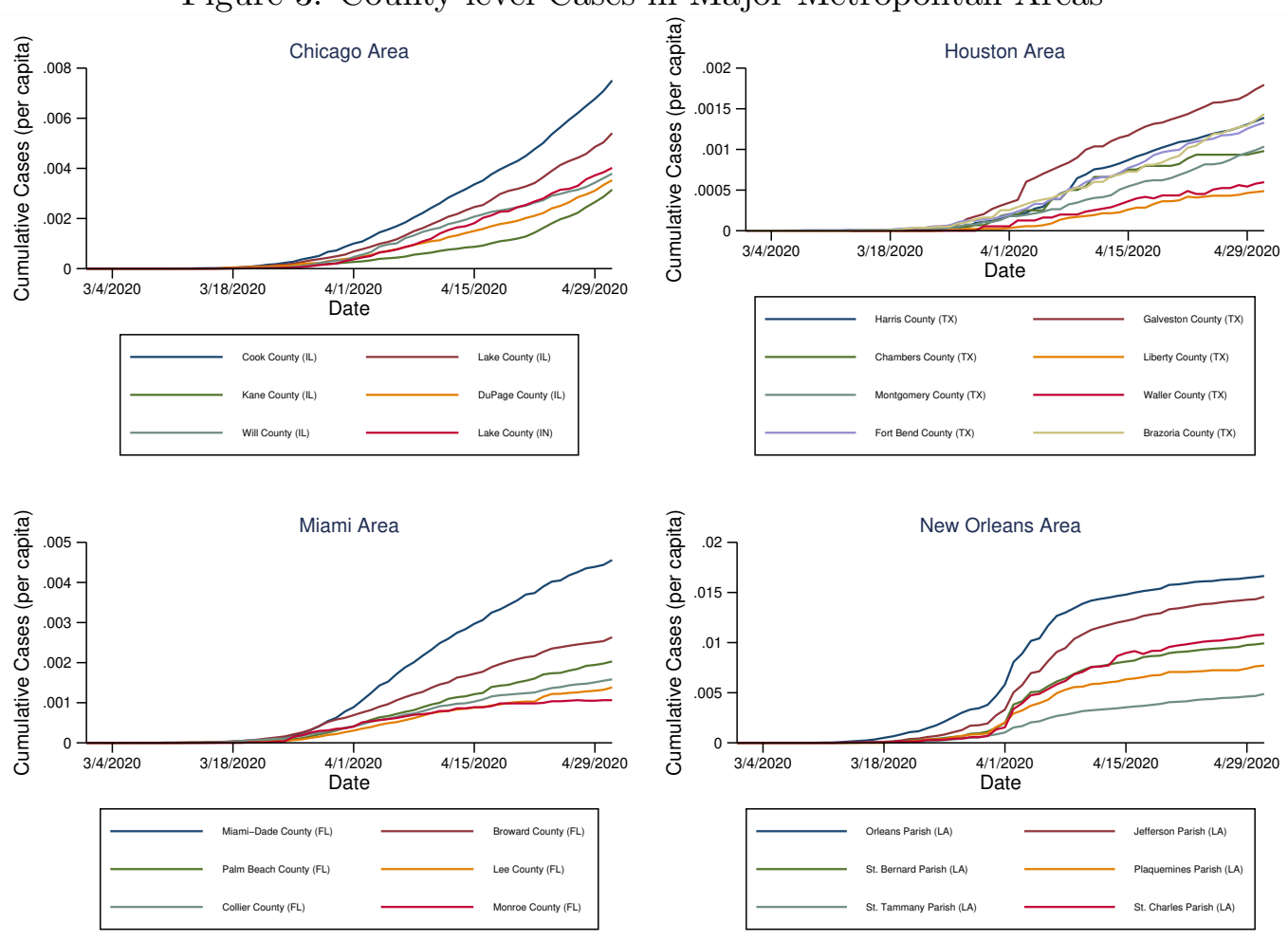

3 plots confirmed county-level cases per-capita over time for four particular metropolitan areas: Chicago, IL (top left); Houston, TX (top right); Miami, FL (bottom left); New Orleans, LA (bottom right). In each case, the county containing the urban center appears to trigger the area outbreak (respectively: Cook County, IL; Harris County, TX; ${ }^{6}$ Miami-Dade County, FL; Orleans Parish, LA). In the case of Chicago, which lies on the Illinois-Indiana border, the spillover appears to extend to Lake County, IN. Together, these figures provide preliminary evidence of transmission dynamics in which Covid-19 cases emanate from major urban centers into the surrounding areas, and across state lines.

\footnotetext{
${ }^{6}$ Here the outbreak appears to stem from both Harris County (Houston) and Galveston County, which is also a fairly densely populated area.
} 
Figure 4: Containment Measures Over Time

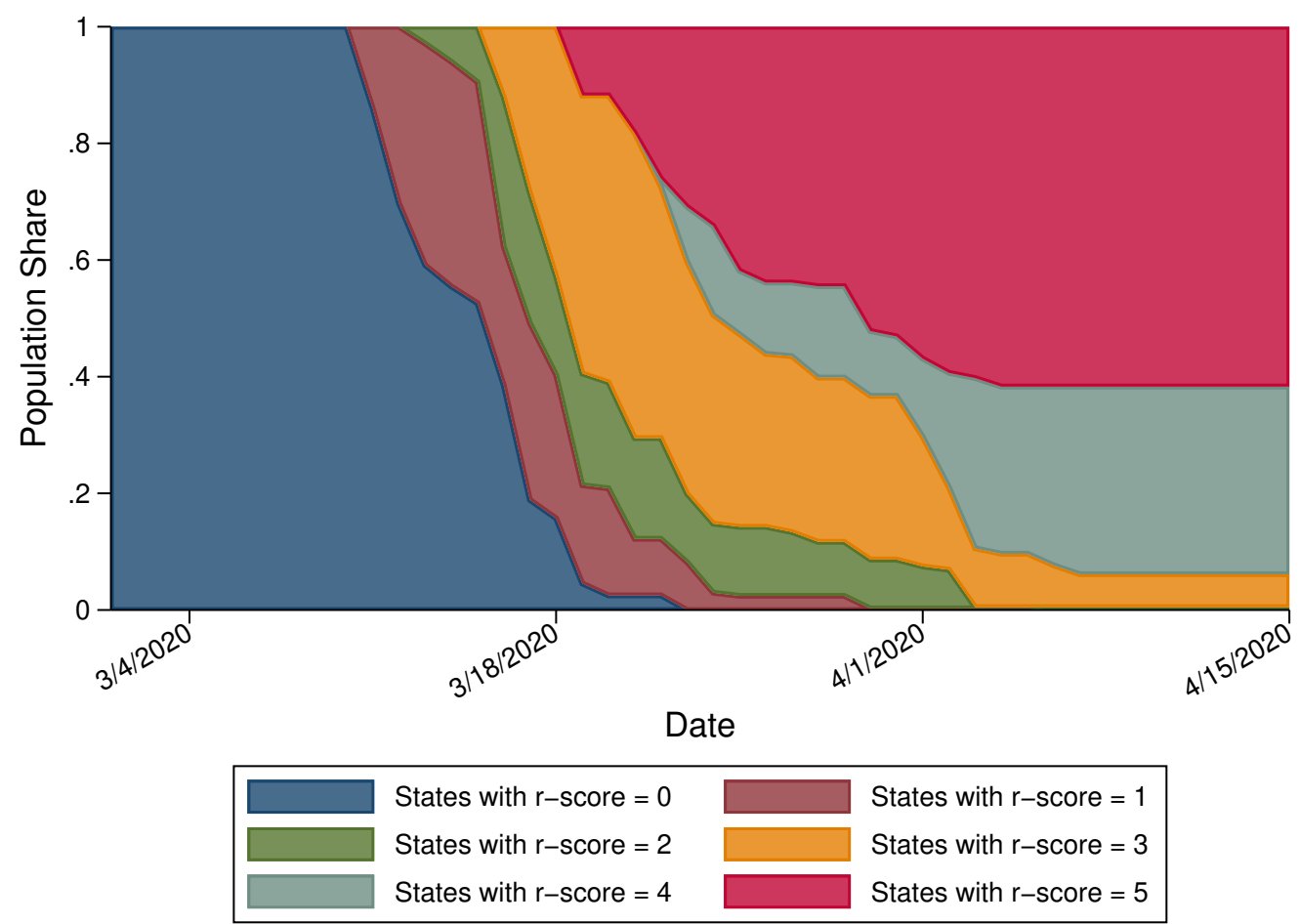

\subsection{Containment measures across time and space}

There is also clear evidence that during the initial shutdown of March and April, government-led containment measures varied geographically and over time. Figure 4 displays the transition from no official containment measures (early March) to universal adoption (of at least some measures) by all states by early April. The most action occurred between mid-March and early April. 60 percent of the U.S. population lived in a state with no containment measures on March 15; however, by April 1 nearly 60 percent of the population lived in a state that had adopted all five factors described by our r-score variable.

In the sections below, our spatial-econometric analysis and our spatial model and calibration exercise seek to understand further the geographical spillovers across county and state lines. For such effects to be meaningful and identifiable, there must be substantial variation in government-led 
Figure 5: Share of U.S. Population Living in a County with Different Containment Measures than its Five Nearest Counties

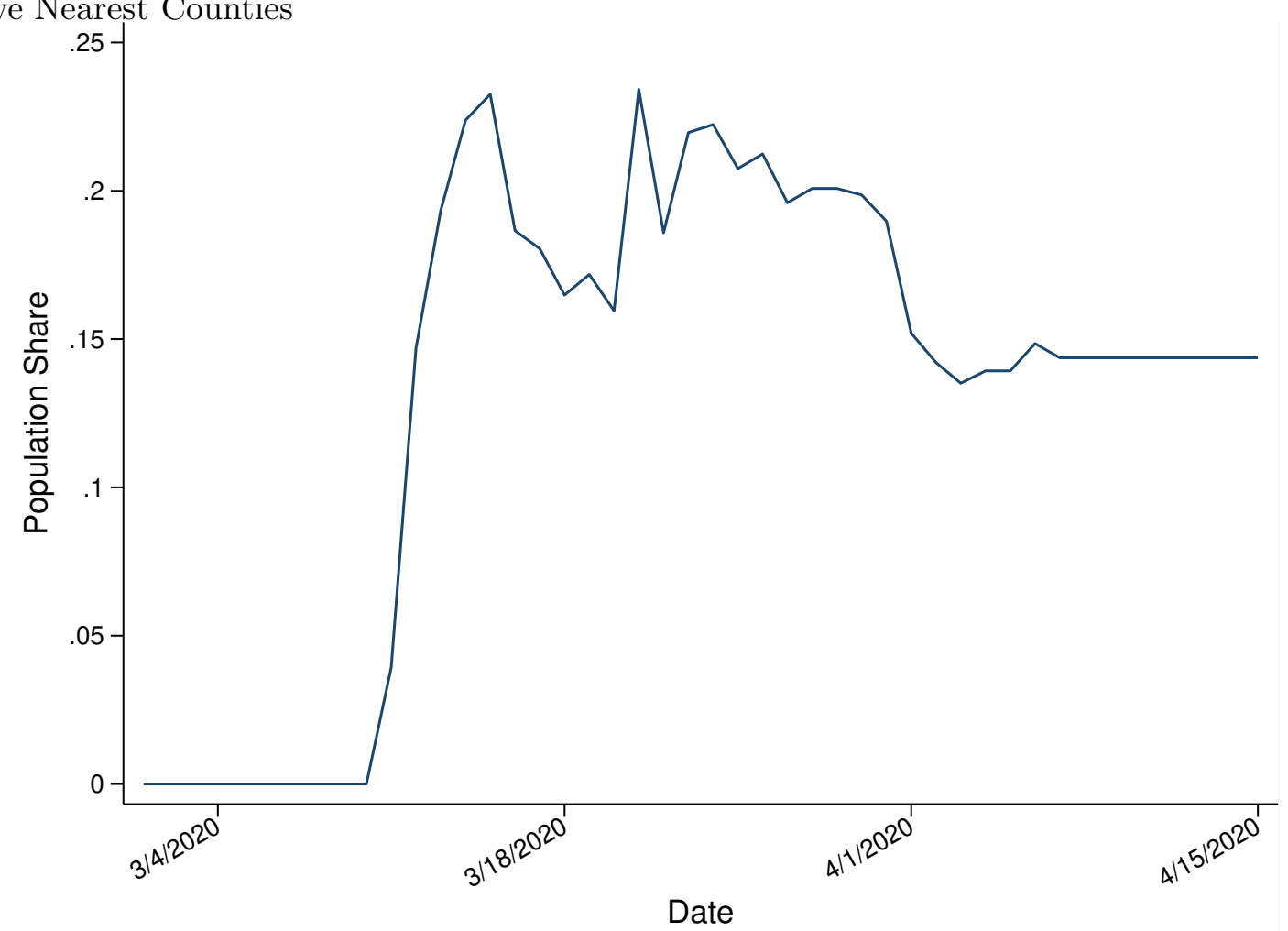

Covid-19 responses near state borders. Figure 5 displays the share of the U.S. population living in a county with a different level of containment measures (i.e., r-score value) than at least one of its five nearest counties, over time. During the containment action period of mid-March through early April, this share quickly rose to about 23 percent of the population, fluctuated between 15 and 23 percent for the next two weeks, and then settled at 15 percent for the remainder of April.

\section{Estimating the Spatial Diffusion of Cases}

In this section and the next we estimate the spatial characteristics of cases. First, we estimate the spillovers of cases from county to county in the United States using oft-used spatial econometric models. Second we then use a VAR-framework to estimate "spatial impulse response functions," which capture the time-series persistence of the spatial spillovers. 


\subsection{Estimation of Spatial Correlation}

For the first exercise, we estimate the following standard spatial models: the Spatial Durbin Model (SDM), the SDM model with spatially correlated errors (SDM Error), the SAR Model, and the SLX model. We start with SDM which, in a panel setting, can be written as:

$$
Y_{t}=\rho W Y_{t}+\beta X_{t}+\theta W X_{t}+\delta+\epsilon_{t}
$$

where $Y_{t}=Y_{1, t}, \ldots, Y_{N, t}$ is a $N T \times 1$ vector of the dependent variable; $W Y_{t}$ is the spatial lag term; $X_{t}$ is an $N T \times r$ matrix of $r$ exogenous variables, $\delta=\delta_{1}, \ldots, \delta_{N}$ is the vector of region-fixed effects; and $W X_{t}$ is the spatial lag term for the exogenous variables, which here we refer to as the "exogenous spatial interaction" term (to distinguish this from the spatial lag variable). ${ }^{7}$ The spatial term $W Y_{t}$ captures the direct effect of the spatial correlation in determining the dependent variable (capturing what otherwise might be an omitted variable). The SDM error model amends the typical SDM to include a spatially correlated error. The SAR model imposes a restriction that $\theta=0$, and the SLX model imposes a restriction that $\rho=0$.

For the models above, $Y_{t}$ is the county level cases, and $X_{t}$ is the r-score. We include a countylevel fixed effect to control for county-level features such as population density, relative industry, employment shares, and so on (given the data sources, such variables are fixed over the time period). We report the baseline spatial results for each model, along with the direct and indirect spatial effects. We also consider additional specifications, including with the r-score lagged 14 days, and with the lag of the dependent variable included as a regressor.

Tables 1 and 2 report the results for the four models. Table 2 displays results with a lag of the dependent variable included in each model; we refer to this as the dynamic version. ${ }^{8}$ We report baseline results shown in Tables 1 and 2 for purposes of comparison with "traditional" approaches

\footnotetext{
${ }^{7}$ See Halleck Vega and Elhorst (2015) for a detailed discussion on the SLX model and the other spatial models employed in this paper.

${ }^{8}$ There are various versions of spatial models with temporal dynamics. Elhorst (2012) refers to a SAR model augmented with temporal lag of the dependent variable and a temporal lag of the spatial lag as the "time-space dynamic model." Pace et al. (1998) provide an example with their "STAR" model. Brady (2014) provides a brief overview of some of these models. See also Debarsy et al. (2012) for discussion.
} 
Table 1: Baseline results for Spatial Models of New Cases (measured as a growth rate)

\begin{tabular}{|c|c|c|c|c|c|c|c|c|}
\hline & SAR & SAR & SLX & SLX & $\mathrm{SDM}$ & $\mathrm{SDM}$ & SDM Error & SDM Error \\
\hline r-score & $\begin{array}{c}-6.223^{* * *} \\
(0.278)\end{array}$ & & $\begin{array}{c}4.280^{* * *} \\
(1.138)\end{array}$ & & $\begin{array}{c}3.851^{* * *} \\
(1.130)\end{array}$ & & $\begin{array}{c}4.938^{* * *} \\
(1.096)\end{array}$ & \\
\hline r-score 14 day lag & & $\begin{array}{c}-6.030^{* * *} \\
(0.273)\end{array}$ & & $\begin{array}{c}2.691^{* *} \\
(1.119)\end{array}$ & & $\begin{array}{c}2.292^{* *} \\
(1.112)\end{array}$ & & $\begin{array}{c}3.192^{* * *} \\
(1.080)\end{array}$ \\
\hline $\mathrm{W} \times$ cases & $\begin{array}{c}0.156^{* * *} \\
(0.00295)\end{array}$ & $\begin{array}{c}0.152^{* * *} \\
(0.00298)\end{array}$ & & & $\begin{array}{c}0.155^{* * *} \\
(0.00295)\end{array}$ & $\begin{array}{c}0.151^{* * *} \\
(0.00298)\end{array}$ & $\begin{array}{c}0.552^{* * *} \\
(0.00497)\end{array}$ & $\begin{array}{l}0.544^{* * *} \\
(0.00515)\end{array}$ \\
\hline $\mathrm{W} \times$ r-score & & & $\begin{array}{c}-12.75^{* * *} \\
(1.203)\end{array}$ & & $\begin{array}{c}-10.99^{* * *} \\
(1.195)\end{array}$ & & $\begin{array}{c}-8.868^{* * *} \\
(1.141)\end{array}$ & \\
\hline $\mathrm{W} \times(\mathrm{r}$-score 14 day lag $)$ & & & & $\begin{array}{c}-10.71^{* * *} \\
(1.183)\end{array}$ & & $\begin{array}{c}-9.077^{* * *} \\
(1.176)\end{array}$ & & $\begin{array}{c}-6.938^{* * *} \\
(1.125)\end{array}$ \\
\hline $\mathrm{W} \times$ error & & & & & & & $\begin{array}{c}-0.521^{* * *} \\
(0.00783)\end{array}$ & $\begin{array}{c}-0.512^{* * *} \\
(0.00803)\end{array}$ \\
\hline $\mathrm{N}$ & 276408 & 276408 & 276408 & 276408 & 276408 & 276408 & 276408 & 276408 \\
\hline
\end{tabular}

Notes: Spatial models estimated from April 1 through June 28, controlling for county-level fixed effects. Dynamic refers to the lag of the dependent variable included in the model. 14 day lag of r-score is the value from 14 days prior. The Wald test for spatial correlation is statistically significant in all models. Standard errors are in parentheses. ${ }^{*} p<.1,{ }^{* *} p<.05,{ }^{* * *} p<.01$. 
Table 2: Dynamic Version of Spatial Models

\begin{tabular}{|c|c|c|c|c|c|c|c|c|}
\hline & SAR & SAR & SLX & SLX & SDM & SDM & SDM Error & SDM Error \\
\hline cases $(t-1)$ & $\begin{array}{c}0.0493^{* * *} \\
(0.00190)\end{array}$ & $\begin{array}{c}0.0488^{* * *} \\
(0.00190)\end{array}$ & $\begin{array}{c}0.0544^{* * *} \\
(0.00191)\end{array}$ & $\begin{array}{c}0.0536^{* * *} \\
(0.00191)\end{array}$ & $\begin{array}{c}0.0493^{* * *} \\
(0.00190)\end{array}$ & $\begin{array}{c}0.0488^{* * *} \\
(0.00190)\end{array}$ & $\begin{array}{c}0.0500^{* * *} \\
(0.00171)\end{array}$ & $\begin{array}{c}0.0495 * * * \\
(0.00171)\end{array}$ \\
\hline r-score & $\begin{array}{c}-5.900 * * * \\
(0.364)\end{array}$ & & $\begin{array}{c}3.183^{* *} \\
(1.344)\end{array}$ & & $\begin{array}{c}2.698^{* *} \\
(1.336)\end{array}$ & & $\begin{array}{c}4.007^{* * *} \\
(1.297)\end{array}$ & \\
\hline r-score 14 day lag & & $\begin{array}{c}-5.940^{* * *} \\
(0.273)\end{array}$ & & $\begin{array}{c}2.629^{* *} \\
(1.118)\end{array}$ & & $\begin{array}{c}2.245^{* *} \\
(1.111)\end{array}$ & & $\begin{array}{c}3.078^{* * *} \\
(1.078)\end{array}$ \\
\hline $\mathrm{W} \times$ cases & $\begin{array}{l}0.150^{* * *} \\
(0.00298)\end{array}$ & $\begin{array}{l}0.148^{* * *} \\
(0.00299)\end{array}$ & & & $\begin{array}{l}0.149^{* * *} \\
(0.00298)\end{array}$ & $\begin{array}{l}0.147^{* * *} \\
(0.00299)\end{array}$ & $\begin{array}{l}0.545^{* * *} \\
(0.00496)\end{array}$ & $\begin{array}{l}0.540^{* * *} \\
(0.00505)\end{array}$ \\
\hline $\mathrm{W} \times \mathrm{r}$-score & & & $\begin{array}{c}-11.30^{* * *} \\
(1.440)\end{array}$ & & $\begin{array}{c}-9.571^{* * *} \\
(1.431)\end{array}$ & & $\begin{array}{c}-7.823^{* * *} \\
(1.364)\end{array}$ & \\
\hline $\mathrm{W} \times(\mathrm{r}$-score 14 day lag $)$ & & & & $\begin{array}{c}-10.50^{* * *} \\
(1.181)\end{array}$ & & $\begin{array}{c}-8.929^{* * *} \\
(1.174)\end{array}$ & & $\begin{array}{c}-6.714^{* * *} \\
(1.123)\end{array}$ \\
\hline $\mathrm{W} \times$ error & & & & & & & $\begin{array}{c}-0.521^{* * *} \\
(0.00777)\end{array}$ & $\begin{array}{c}-0.515^{* * *} \\
(0.00785)\end{array}$ \\
\hline $\mathrm{N}$ & 276408 & 276408 & 276408 & 276408 & 276408 & 276408 & 276408 & 276408 \\
\hline
\end{tabular}

Notes: Spatial models estimated from April 1 through June 28, controlling for county-level fixed effects. Dynamic refers to the lag of the dependent variable included in the model. 14 day lag of r-score is the value from 14 days prior. The Wald test for spatial correlation is statistically significant in all models. Standard errors are in parentheses. ${ }^{*} p<.1,{ }^{* *} p<.05$, *** $p<.01$. 
to spatial estimation, of which these models represent. However, as emphasized in LeSage and Pace (2009) and elaborated upon in the spatial literature since, one should not use these "baseline" results to interpret the spatial effects. As explained in detail by Golgher and Voss (2016), one cannot interpret the coefficients as typical partial derivatives (see Elhorst (2010) or Elhorst (2014), for additional explanation). Instead, it is more appropriate to focus on the direct and indirect effects of these models.

Table 3 displays those direct and indirect spatial effects from estimating each model. The direct effect is the effect of a change in explanatory variable $X$, in county $i$, on the number of new Covid-19 cases in county $i$. The indirect effect is, instead, the effect of the change in explanatory variable $X$, in county $j$, on the average case levels in surrounding states. The indirect effect is the spatial spillover. We eschew discussing the details of how to derive these effects; instead, we refer the reader to Golgher and Voss (2016), LeSage and Pace (2009), or Elhorst (2010) for technical explanations. ${ }^{9}$

In all cases, we employ a contiguity matrix (row-normalized) since this version of the spatialweighting matrix is the most common in the spatial literature though we considered other versions for robustness (such as an inverse-distance-based matrix), but do not report those results here for brevity. Tables 1 and 2 help underscore the spatial spread of county-level Covid-19 cases - all parameters are statistically significant across the various models. The Wald test for spatial correlation is statistically significant for each model (the Wald results are not shown explicitly in Tables 1 and 2). As noted, we eschew focusing on the parameter estimates from Tables 1 and 2 an instead focus on the direct and indirect effects reported in Table 3.

As displayed in Table 3, the direct effect of the r-score - the "own" county effect-is negative in the SAR model, but positive in the other models. This may reveal these estimates are affected by endogeneity between the r-score and the change in cases each day - that is, state governments

\footnotetext{
${ }^{9}$ For a "crib-note" version of these effects, the direct effect for the SDM model shown above can be expressed as, $\left(\frac{3-\rho^{2}}{1-\rho^{2}}\right) \beta_{k}+\left(\frac{3 \rho}{3\left(1-\rho^{2}\right)}\right) \theta_{k}$, which is a re-print from Elhorst (2010) using an example with three regions. And, the indirect effect (again, from Elhorst $(2010)$ ) is, $\left(\frac{3 \rho-\rho^{2}}{3\left(1-\rho^{2}\right)}\right) \beta_{k}+\left(\frac{3+\rho}{3\left(1-\rho^{2}\right)}\right) \theta_{k}$. The point, here, is the direct and indirect effects are a combinations of the baseline model parameters.
} 
Table 3: Direct and Indirect Spatial Effects

\begin{tabular}{|c|c|c|c|c|c|c|c|c|}
\hline & SAR & SLX & SDM & SDM Error & SAR & SLX & SDM & SDM Error \\
\hline & \multicolumn{4}{|c|}{ Baseline } & \multicolumn{4}{|c|}{ Baseline with 14 day lag of r-score } \\
\hline \multicolumn{9}{|l|}{ Direct } \\
\hline \multirow{2}{*}{ r-score } & -2.039 & 1.155 & 0.880 & 1.202 & -6.055 & 2.691 & 2.055 & 2.523 \\
\hline & 0.000 & 0.300 & 0.415 & 0.232 & 0.000 & 0.016 & 0.058 & 0.013 \\
\hline \multicolumn{9}{|l|}{ Indirect } \\
\hline \multirow{2}{*}{ r-score } & -0.370 & -3.900 & -3.606 & -4.030 & -1.051 & -10.701 & -10.036 & -10.729 \\
\hline & 0.000 & 0.001 & 0.002 & 0.000 & 0.000 & 0.000 & 0.000 & 0.000 \\
\hline \multicolumn{9}{|l|}{ Total } \\
\hline \multirow[t]{4}{*}{ r-score } & -2.409 & -2.745 & -2.727 & -2.827 & -7.106 & -8.011 & -7.981 & -8.206 \\
\hline & 0.000 & 0.000 & 0.000 & 0.000 & 0.000 & 0.000 & 0.000 & 0.000 \\
\hline & SAR & SLX & $\mathrm{SDM}$ & SDM Error & SAR & SLX & $\mathrm{SDM}$ & SDM Error \\
\hline & \multicolumn{4}{|c|}{ Dynamic } & \multicolumn{4}{|c|}{ Dynamic with 14 day lag of $r$-score } \\
\hline \multirow[t]{2}{*}{$\begin{array}{l}\text { Direct } \\
\text { cases (t-1) }\end{array}$} & 0.049 & 0.054 & 0.049 & 0.054 & 0.049 & 0.054 & 0.049 & 0.053 \\
\hline & 0.000 & 0.000 & 0.000 & 0.000 & 0.000 & 0.000 & 0.000 & 0.000 \\
\hline \multirow[t]{2}{*}{ r-score } & -5.924 & 3.183 & 2.452 & 3.280 & -5.963 & 2.629 & 2.018 & 2.436 \\
\hline & 0.000 & 0.018 & 0.060 & 0.007 & 0.000 & 0.019 & 0.063 & 0.016 \\
\hline \multirow{3}{*}{$\begin{array}{l}\text { Indirect } \\
\text { cases }(\mathrm{t}-1)\end{array}$} & & & & & & & & \\
\hline & 0.008 & - & 0.008 & 0.056 & 0.008 & - & 0.008 & 0.055 \\
\hline & 0.000 & - & 0.000 & 0.000 & 0.000 & - & 0.000 & 0.000 \\
\hline \multirow[t]{2}{*}{ r-score } & -1.016 & -11.294 & -10.522 & -11.656 & -1.005 & -10.493 & -9.845 & -10.336 \\
\hline & 0.000 & 0.000 & 0.000 & 0.000 & 0.000 & 0.000 & 0.000 & 0.000 \\
\hline \multirow[t]{2}{*}{$\begin{array}{l}\text { Total } \\
\text { cases }(\mathrm{t}-1)\end{array}$} & 0.058 & 0.054 & 0.058 & 0.110 & 0.057 & 0.054 & 0.057 & 0.108 \\
\hline & 0.000 & 0.000 & 0.000 & 0.000 & 0.000 & 0.000 & 0.000 & 0.000 \\
\hline \multirow[t]{2}{*}{ r-score } & -6.940 & -8.111 & -8.070 & -8.376 & -6.969 & -7.865 & -7.826 & -7.900 \\
\hline & 0.000 & 0.000 & 0.000 & 0.000 & 0.000 & 0.000 & 0.000 & 0.000 \\
\hline
\end{tabular}

Notes: Spatial models estimated from April 1 through June 28, controlling for county-level fixed effects. P-values are in italics. Dynamic refers to the lag of the dependent variable included in the model. 14 day lag of $\mathrm{r}$-score is the value from 14 days prior. 
are responding to their own case counts in determining the lock-down measures).

However, the indirect effect - the spatial spillover - of a change in the r-score in surrounding counties is negative in each model (with either the 14-day lag of the score or the current value). Note, for this variable in particular, the spillover will come from adjacent counties in other states, since our r-score variable will be identical for counties within a state. For the dynamic versions, the results are similar with respect to the signs of the effects - though for the r-score estimates (direct and indirect) the magnitudes are affected by the including of the temporal lag of cases.

The results from the standard spatial models indicate the relevance of spillovers related to the spread of Covid-19. This is not necessarily surprising, but this exercise provides clear statistical evidence on the spatial relationships not only between the spread of cases across regions but also how that spread was affected by the closure policies of adjacent states.

To further understand the spatial characteristics of the growth rate of new cases across counties, in the next section we consider the spatial "diffusion" of new cases across counties - that is, the temporal response of county $i$ 's cases in response to a change to its neighbors' caseloads.

\subsection{Estimation of Spatial Impulse Response Functions}

To estimate the temporal diffusion of the spatial connection between counties, we follow Brady (2014), Holly et al. (2011), Kuethe and Pede (2011), and Pollakowski and Ray (1997), and use an autoregressive-based strategy to measure the dynamics of spatial spillovers. While each of those studies focused on housing market spillovers, the methods therein are easily applicable to the county-level data on Covid-19 cases. In the latter three papers, a region's dependent variable is modeled as a function of the same variable in surrounding regions and the impulse response functions calculated to measure the spatial spillovers are estimated from a VAR.

In this application, we focus on single-equation estimation since, as demonstrated in Auerbach and Gorodnichenko (2012), and Brady (2011, 2014), one can easily generate impulse response functions in the single-equation setting using Jordà (2005) local linear projections technique (as opposed to employing a fully-specified VAR). The basic motivation is that impulse response estimates can be 
produced from a single equation by projecting the endogenous variables in a system onto their lags for each horizon, $h$. Specifically, to paraphrase Auerbach and Gorodnichenko (2012), if $j=1, \ldots, h$, and you are estimating some dependent variable as a function of its own lag and some other factor, $X$, then the IRF is estimated from the sequence of regressions:

$$
\begin{gathered}
Y_{t+1}=\rho_{1} Y_{t-1}+\beta_{1} X_{t}+\epsilon_{t} \\
Y_{t+2}=\rho_{2} Y_{t-1}+\beta_{2} X_{t}+\epsilon_{t} \\
\vdots \\
Y_{t+h}=\rho_{h} Y_{t-1}+\beta_{h} X_{t}+\epsilon_{t}
\end{gathered}
$$

The impulse response estimates of the response of $Y$ to a "shock" to $X$ are, $I R F=\hat{\beta}_{1}, \hat{\beta}_{2}, \ldots, \hat{\beta}_{h}$. This sequence of coefficient estimates approximates the impulse response coefficients you would recover from a VAR using recursive methods (under the null hypothesis as noted by Auerbach and Gorodnichenko (2012), which assumes the data generating processes are the same). However, the sequence estimated directly is not "tied" to the recursive structure of the VAR-generated impulse response functions - which is one reason Jordà (2005) mentions the the direct estimates are less subject to mis-specification.

Plagborg-Møller and Wolf (2019) provide a detailed discussion on the comparison between VAR-generated IRFs and the local projection approach; Rana and Shea (2015), Haug and Smith (2012) and Jordà et al. $(2016,2020)$ are other examples of the local projection technique. In the spatial-oriented literature, Brady $(2011,2014)$ estimate local projection-generated impulse response functions from SAR and dynamic SDM models for housing price data at the county level and state level in the U.S., respectively.

We first estimate county $i$ 's growth rate of new cases as a function of the same variable in its five nearest neighbors, and the $t-l$ lag of each, along with a county-level fixed effect. We define "nearest neighbors" by distance, using geospatial coordinates to identify the closest neighboring 
Figure 6: Response of county $i$ 's new cases to a shock to new cases to cases its $j$ th-nearest neighboring county
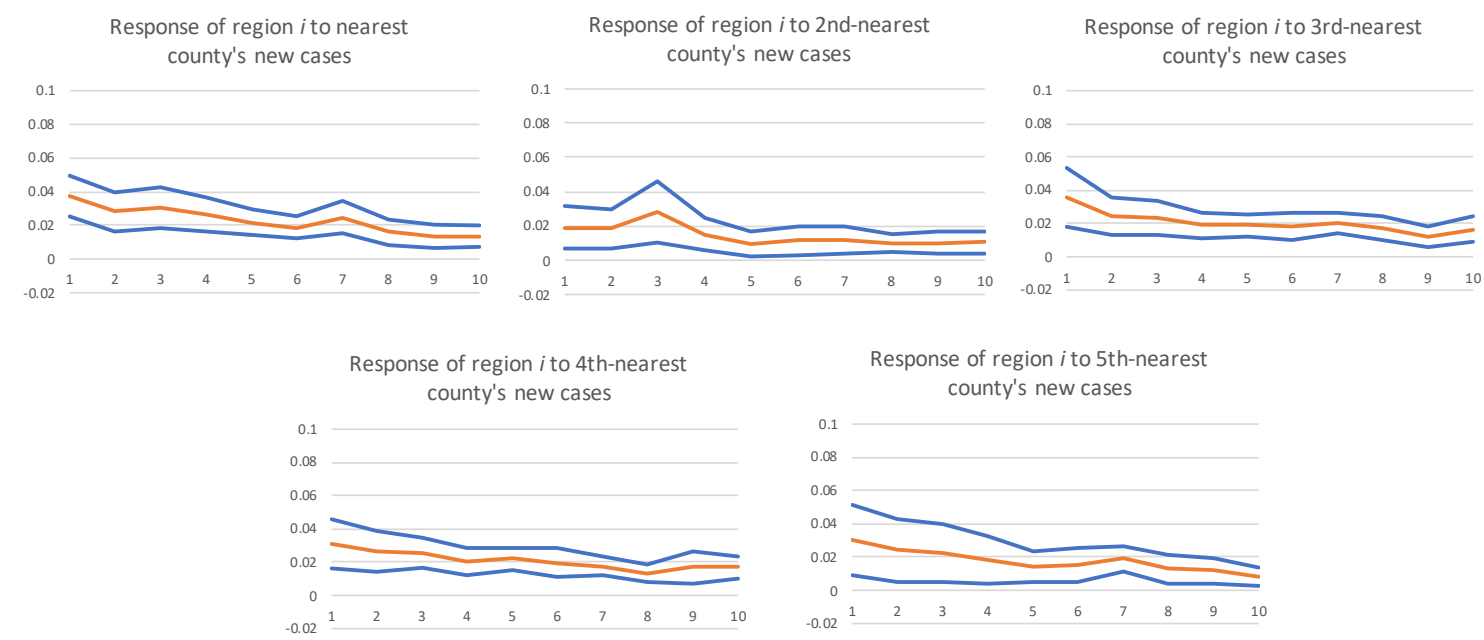

Notes: Estimated from single-equation autoregressive-distributed lag model with the time $t$ and $t$ - 1 values of each independent variable (each neighbor), and including a county level fixed effect. Nearest neighbor is measured by distance. New Cases measured as a simple growth rate.

county, the next closest, the third closest and so on up to the fifth closest neighbor. ${ }^{10}$

As an alternative, we eschew the fixed effect and instead include the following county and state level variables: the r-score for county $i$ and the r-scores of its five-closest neighbors; the population density of county $i$ and the population density of the five closest neighbors; the share of county $i$ 's population over the age of 60; and the share of voters in county $i$ that voted Republican in the 2016 presidential election.

Figure 6 reports the IRFs of county $i$ 's response to new cases in its nearest five neighbors over a forecast horizon of ten days (95 percent confidence intervals are constructed using Driscoll-Kraay standard errors). These results are from the specification that includes the county-level fixed effect. For each of the nearest five neighbors, the response of new cases in county $i$ increases and this increase persists for the duration of the forecast horizon (with a gradual decay). The effect of each

\footnotetext{
${ }^{10}$ This is similar to Pollakowski and Ray (1997) who include the lags of price changes in adjacent regions included as regressors in an equation for a change in housing prices across regions within the United States. Kuethe and Pede (2011) do something similar in their study of housing prices in the western part of the United States, as do Holly et al. (2011) in their analysis of housing prices in the United Kingdom. One difference from our estimation with Holly et al. (2011) is we do not specify a "dominant" region, since we wish to leave the possible spread "unconstrained" in the estimation.
} 
Figure 7: Response of county $i$ 's new cases to a shock to new cases to cases its $j$ th-nearest neighboring county: county and state controls
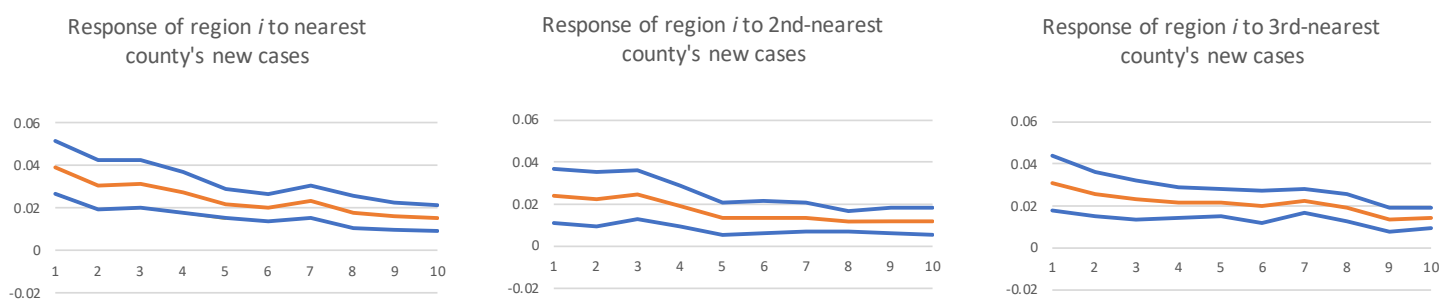

Response of region $i$ to 4th-nearest county's new cases

Response of region $i$ to 5th-nearest county's new cases
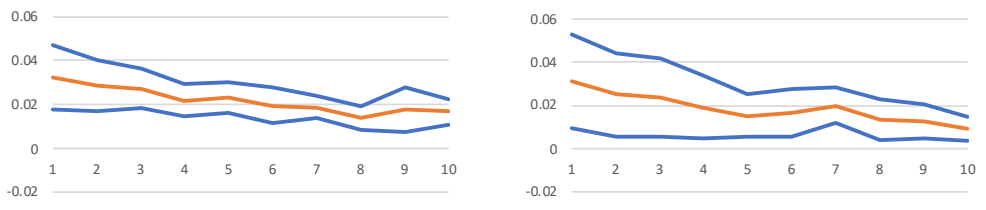

Notes: Estimated using local projection technique from single-equation autoregressive-distributed lag model; specifications included county and state level controls. See text for details. Nearest neighbor is measured by distance. New cases measured as simple growth rate. Sample from March 31st through June 28th.

neighbor on county $i$ 's cases is about the same, which makes sense from a geographic perspective. Since the "nearest" is measured using latitude and longitude coordinates, in general the nearest neighbors will be those that surround the county in its own state or in bordering states. In other words, the IRFs reveal that spillovers, on average, appear to come from all sides of county $i$. With respect to the magnitudes, recall that "new cases" is measured as a simple day-to-day growth rates.

Figure 7 displays the same estimates, but for the specification with county-level and state-level covariates. The responses do not differ much compared to those displayed in Figure 6. With respect to the response of the new cases in county $i$ to the other covariates, only for the r-score can we report any meaningful dynamics. The population density and the other shares-variables mentioned above do not vary over time in our sample.

For the r-score, which is a state-level variable, we find that only the within-state r-score matters for the growth rate of new cases. Figure 7 displays this response. At each horizon the response is negative. It is worth noting, of course, that the dynamics of the r-score variable are "lumpy" - the r-score changes at discrete and infrequent intervals, with the frequency and the value depending on 
Figure 8: Response of County New Cases to state-level r-score

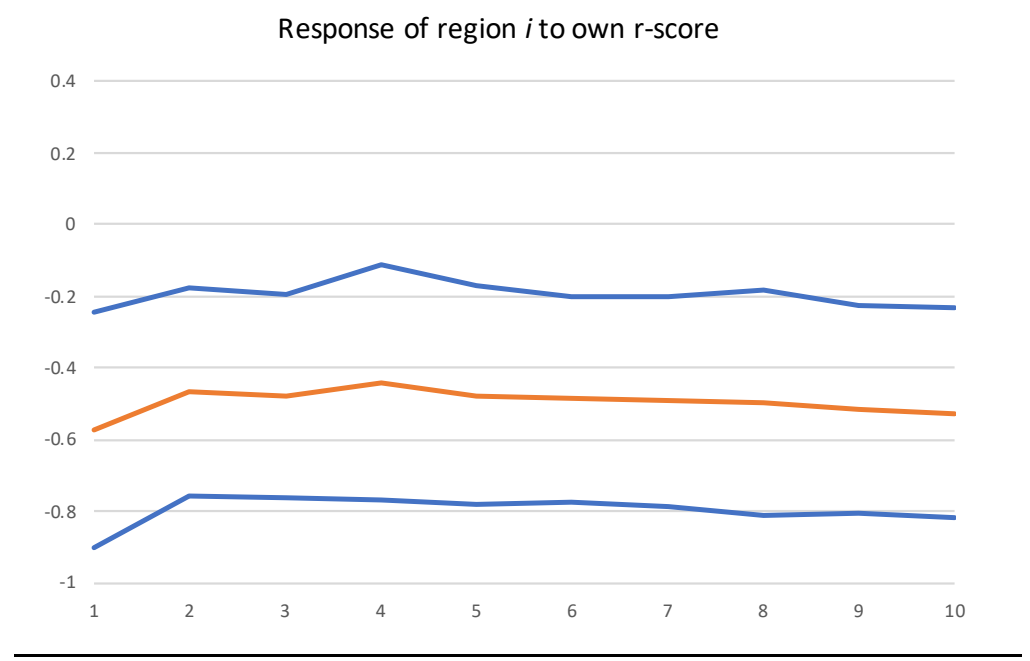

Notes: See text for definition of $r$-score

the state. Moreover, we find little response of the response of county $i$ 's new cases to the r-score of counties in surrounding states (therefore, we do not report these figures). This, too, may not be surprising since this effect will only record the relationship between "nearest neighbors" if those counties are in different states. We also consider a variation of this relationship and isolate only those counties that had a nearest neighbor in a state where the r-score differs by two or more. However, we find no statistically significant relationship in that case either.

On balance, the "spatial" IRFs support the notion that the number of new cases easily spread across counties and states and provide a "stylized" picture of that spatial diffusion - the spatial diffusion is statistically significant and persistent over time. The spatial IRFs provide an alternative perspective from the "static" spatial models estimated in section 3. Considered together, however, both the traditional "off-the-shelf" spatial models and the spatial IRFs provide an informative picture on the nature of the spatial correlation of the Covid-19 phenomenon. As an added perspective, too, the estimation provides some insight into the effectiveness of the state-level closures - more stringent measures are consistent with a decline in the growth rate of new cases at the county level. 


\section{Spatial SIR and Counterfactual Experiments}

The previous sections provide evidence of a substantial degree of inter-state spillovers of Covid-19 across regions. In this section, motivated by that evidence, we construct and calibrate a structural SIR model, similar to the one described in Atkeson (2020b), Eichenbaum et al. (2020), Glover et al. (2020), or Fernández-Villaverde and Jones (2020), but with a few modifications. Most importantly, the model allows for infections across state boundaries. We then use the model to evaluate the extent to which the presence of such spillovers contributed to the spread of the infections in the U.S. and within each state. We also evaluate how lock-down policies implemented in one state impact the rest of the country.

At this stage, our results need to be treated with some caution. The outbreak is still in its early phase, and our data covers only the first 5 months, with many unreported cases, and with a possibly large but unknown number of cases "imported" from other countries (the model only considers internal transmission). We abstract from a number of features that affect the spread of the disease over time, such as voluntary changes in people's behavior ${ }^{11}$ or the change in infectiousness of people who are still infected. Additionally, as pointed out by Fernández-Villaverde and Jones (2020), the identification of parameters in the compartmental models such as the SIR model can be challenging (this is mostly discussed by Atkeson (2020a) in the context of estimating the fatality rate, which is not the central point of our analysis). We partially address this last issue by considering alternative specifications that differ with respect to the free parameters, and by exploring how those specifications affect different parts of the model fit. We believe our preliminary analysis can still provide useful insights into both the nature and the potential magnitude of inter-state spillovers.

\footnotetext{
${ }^{11}$ We account to some extent for the impact of changes in social distancing measures and the state-specific effectiveness of those.
} 


\subsection{The model}

The model is an extension of the SIR model that allows us to account for the spatial diffusion of infections. We specify the model in discrete, rather than continuous time. In each period $t$, the initial population of region $n$ is divided into four disjoint sets: Susceptible $(S)$, Infected $(I)$, Recovered $(R)$, and Dead $(D)$ :

$$
\operatorname{Pop}_{n, 0}=S_{n, t}+I_{n, t}+R_{n, t}+D_{n, t}
$$

and population at time $t$ is: $\operatorname{Pop}_{n, t}=S_{n, t}+I_{n, t}+R_{n, t}$. The new infections in state $n$ result from interactions between susceptible people $S_{n}$ in that state, with infected people in potentially all other states $I_{n^{\prime}}$, where $n^{\prime}=1, \ldots, N$. The new infections in state $n$ at time $t$ are given by:

$$
I_{n, t}^{n e w}=\frac{S_{n, t}}{P o p_{n, t}} \cdot \sum_{n^{\prime}} \rho\left(n^{\prime}, n\right) \cdot \sqrt{\beta_{n} \beta_{n^{\prime}}} \cdot \sqrt{\kappa_{n, t} \kappa_{n^{\prime}, t}} \cdot I_{n^{\prime}, t}
$$

In the expression above, the whole term $\rho\left(n^{\prime}, n\right) \cdot \sqrt{\beta_{n} \beta_{n^{\prime}}} \cdot \sqrt{\kappa_{n, t} \kappa_{n^{\prime}, t}}$ describes the average number of close contacts that a person from state $n$ has with a person from state $n^{\prime}$ in day $t$. The close contact is defined as one that would result in a transmission of a virus from an infected person to a healthy person. The new infections in state $n$ then occur when an infected person from state $n^{\prime}$ - $I_{n^{\prime}, t}$ - comes in a close contact with a susceptible person from state $n$. The probability that a person we come in a close contact with is susceptible is $\frac{S_{n, t}}{P o p_{n, t}}$.

The parameter $\beta_{n}$ measures the average number of distinct inter-personal contacts that any person in state $n$ has on a regular day. We allow this parameter to vary across states, given the substantial heterogeneity in the fraction of people living in densely populated areas. We expect, of course, that a typical person in New York will have more distinct inter-personal contacts than a person living in Montana. At this stage we assume $\beta_{n}$ is constant over time. It is certainly possible that the typical number of inter-personal contacts will vary over time in each state, and it is quite likely that this variation will differ by state (for example, the value of $\beta$ would likely plummet during the Spring Break in college towns but skyrocket in the nightclubs or bars in Florida). Given how specific this time variation would be to individual states, we have decided 
to assume it away, and only allow the model to have a cross-sectional variation in $\beta$, which yields 49 parameters to be calibrated. We also consider a simpler specification, with three rather than 49 parameters, where $\beta_{n}$ is a polynomial function of the population density in region $n$ : $\beta_{n}=$ $b_{0}+b_{1} \log ($ density $)+b_{1} \log (\text { density })^{2}$.

Next, $\kappa_{n, t}$ measures the degree to which the personal interactions are reduced by the implemented lock-down policies. The actual reduction in the personal interactions results from a combination of two factors: the official lock-down policies and their effectiveness in the particular region. That effectiveness (from the perspective of the model) can capture at least two important factors. The first factor is related to individuals' compliance and the region's enforcement of social distancing measures. The second factor is related to the fact that each social distancing measure (as recorded in our data) comes with exceptions. Those exceptions may be different in different states, or the same exception can have a different coverage in different states. In general, we should not expect the same restriction that we code as a particular value of the r-score variable to have an identical impact in each state. While we cannot speak to the reasons behind that heterogeneity, we can incorporate it in a straightforward fashion into our model. In order to do that we model $\kappa_{n, t}$ as follows:

$$
\kappa_{n, t}=\left(1-\xi_{n}\right)+\xi_{n} \cdot \sum_{i=0}^{5} \kappa^{i} \cdot 1_{\{i\}}\left(\mathrm{r}_{-} \text {score }_{n, t}\right)
$$

where $i$ is the value of the r-score variable ( 0 through 5$), \kappa^{i}$ is the benchmark effect of restriction $i$ in the region where restrictions are most effective, $\xi_{n}$ is the relative effectiveness of restrictions in region $n$, and $1_{\{i\}}(\cdot)$ is a characteristic function of a singleton set with element $i$ (essentially, $1_{\{i\}}\left(\mathrm{r}_{\text {-score }}, t\right)$ equals 1 if $\mathrm{r}$-score sct, $_{n}=i$ and 0 otherwise $)$. We normalize $\xi_{n}=1$ in one of the regions (determined endogenously), and calibrate the 48 remaining values. We also normalize $\kappa^{0}=1(i=0$ corresponds to no restrictions). We also impose a restriction that $\kappa^{i+1} \leq \kappa^{i}$, so a tighter restriction would never lead to more contacts between people. Overall, this adds $48+5=53$ additional parameters to the calibration. We also consider a simpler specification where $\xi_{n}=1$ in every region $n$. 
Finally, $\rho\left(n^{\prime}, n\right)$ denotes the spillover parameter from state $n^{\prime}$ to $n$. We restrict the possible values for $\rho\left(n^{\prime}, n\right)$. First, we normalize $\rho(n, n)=1$. Next, we set $\rho\left(n^{\prime}, n\right)=0$ when two states $n^{\prime}$ and $n$ are not adjacent and we require it to be positive (even if arbitrarily small) when they are. In that case, we set $\rho\left(n^{\prime}, n\right)=\rho \cdot \frac{1}{\sum_{m} 1_{\{x \in \mathbb{R}: x>0\}}\left(\rho\left(n^{\prime}, m\right)\right)}$, where $\rho>0$ will be the parameter to be calibrated. In words, the spillover from state $n^{\prime}$ to state $n$ is divided by the total number states that the state $n^{\prime}$ is adjacent to. We do that in order to ensure that if Virginia and Maryland were one state, the total spillover from DC would be the same as it is when they are two separate states. ${ }^{12}$

The full dynamics of the model are described by the following equations:

$$
\begin{aligned}
S_{n, t+1} & =S_{n, t}-I_{n, t}^{n e w} \\
I_{n, t+1} & =I_{n, t}-\pi_{R} \cdot I_{n, t}-\pi_{D} I_{n, t}+I_{n, t}^{n e w} \\
R_{n, t+1} & =R_{n, t}+\pi_{R} \cdot I_{n, t} \\
D_{n, t+1} & =D_{n, t}+\pi_{D} \cdot I_{n, t} \\
\operatorname{Pop}_{n, t+1} & =\operatorname{Pop}_{n, t}-\pi_{D} \cdot I_{n, t}
\end{aligned}
$$

where $\pi_{R}$ is the daily recovery rate and $\pi_{D}$ is the daily death rate. We set $\pi_{R}=0.03267$ and $\pi_{D}=0.00067$, so that the model implies a $2 \%$ mortality and a 30 -day duration of an average infection.

\subsection{Calibration, model Fit and Parameter Values}

We calibrate the model by minimizing the sum of squared errors between the data and the modelgenerated series of both the cumulative and the new confirmed cases per-capita in each region and in the entire country. In the benchmark calibration our vector of parameters has 103 elements: ${ }^{13}$

$$
\theta:=\left[\rho, \beta_{1}, \ldots, \beta_{49}, \kappa_{1}, \ldots, \kappa_{5}, \xi_{1}, \ldots, \xi_{48}\right]
$$

\footnotetext{
${ }^{12}$ Allowing for $\rho\left(n^{\prime}, n\right)$ to have distinct value for each pair of states would yield $49 \times 24=1,176$ parameters to be calibrated if we assume symmetric spillovers, and double that if we do not.

${ }^{13}$ The two alternative calibrations we consider have the following parameter vectors: $(1) \theta:=\left[\rho, \beta_{1}, \ldots, \beta_{49}, \kappa_{1}, \ldots, \kappa_{5}\right]$ when we assume that $\xi_{n}=1$ in each region $n$, and (2) $\theta:=\left[\rho, b_{0}, b_{1}, b_{2}, \kappa_{1}, \ldots, \kappa_{5}\right]$ when we additionally assume that $\beta_{n}=b_{0}+b_{1} \log ($ density $)+b_{1} \log (\text { density })^{2}$.
} 
In our calibration we assume that the confirmed cases per-capita in each state lag the infections by 14 days and we start our analysis on February 1, 2020 under the assumption that the cumulative infections on that day corresponded to confirmed cases on February 14, 2020. Our two main outcome variables are then defined as:

$$
y_{n, t}:=\frac{I_{n, t-7}}{P_{o p}, 0} \quad \text { and } \quad Y_{t}:=\frac{\sum_{n} I_{n, t-7}}{\sum_{n} \operatorname{Pop}_{n, 0}}, \quad t=15,16, \ldots
$$

The sum of squared errors between the model and the data is then calculated as:

$$
\begin{aligned}
S S E(\theta) & =\sum_{n}\left(\sum_{t=15}^{T}\left(y_{n, t}^{m}(\theta)-y_{n, t}^{d}\right)^{2}+\sum_{t=16}^{T}\left(\Delta y_{n, t}^{m}(\theta)-\Delta y_{n, t}^{d}\right)^{2}\right) \\
& +\sum_{t=15}^{T}\left(Y_{t}^{m}(\theta)-Y_{t}^{d}\right)^{2}+\sum_{t=16}^{T}\left(\Delta Y_{t}^{m}(\theta)-\Delta Y_{t}^{d}\right)^{2}
\end{aligned}
$$

The vector of calibrated parameters $\hat{\theta}$ is then given as

$$
\hat{\theta}:=\arg \min _{\theta} S S E(\theta)
$$

The results of the calibration are reported in Table 4, which displays the overall fit of the model as well as the values of selected parameters, except for the individual regions' values of $\beta_{n}$ and $\xi_{n}$. The latter are reported in the appendix. Here, we plot state-specific parameter values against each region's measure of population density in the two panels of Figure $9 .^{14}$ The parameter values by themselves do not mean much, so we defer their discussion to Section 4.3 where we perform counterfactual simulations. There are two main takeaways here. First, the calibrated values of $\kappa$ 's are much smaller in our benchmark calibration (when we allow $\xi_{n}$ to vary by state) than when we assume identical, perfect effectiveness of each restriction $\left(\xi_{n}=1\right.$ for all $\left.n\right)$. This is not surprising at all; higher values $\kappa$ 's in the first two columns of Table 4 reflect the fact that in the average state the effectiveness of that restriction measure is not perfect. Second, modeling $\beta_{n}$ as a fixed effect rather than a simple polynomial function of the population density makes a huge difference in terms of the model's ability to account for the variation of Covid-19 cases across states.

\footnotetext{
${ }^{14}$ We compute the population density for each state as a population-weighted average of the density in each county.
} 
Figure 9: State-specific values of $\beta_{n}$ and $\xi_{n}$ vs. $\log$ of population density
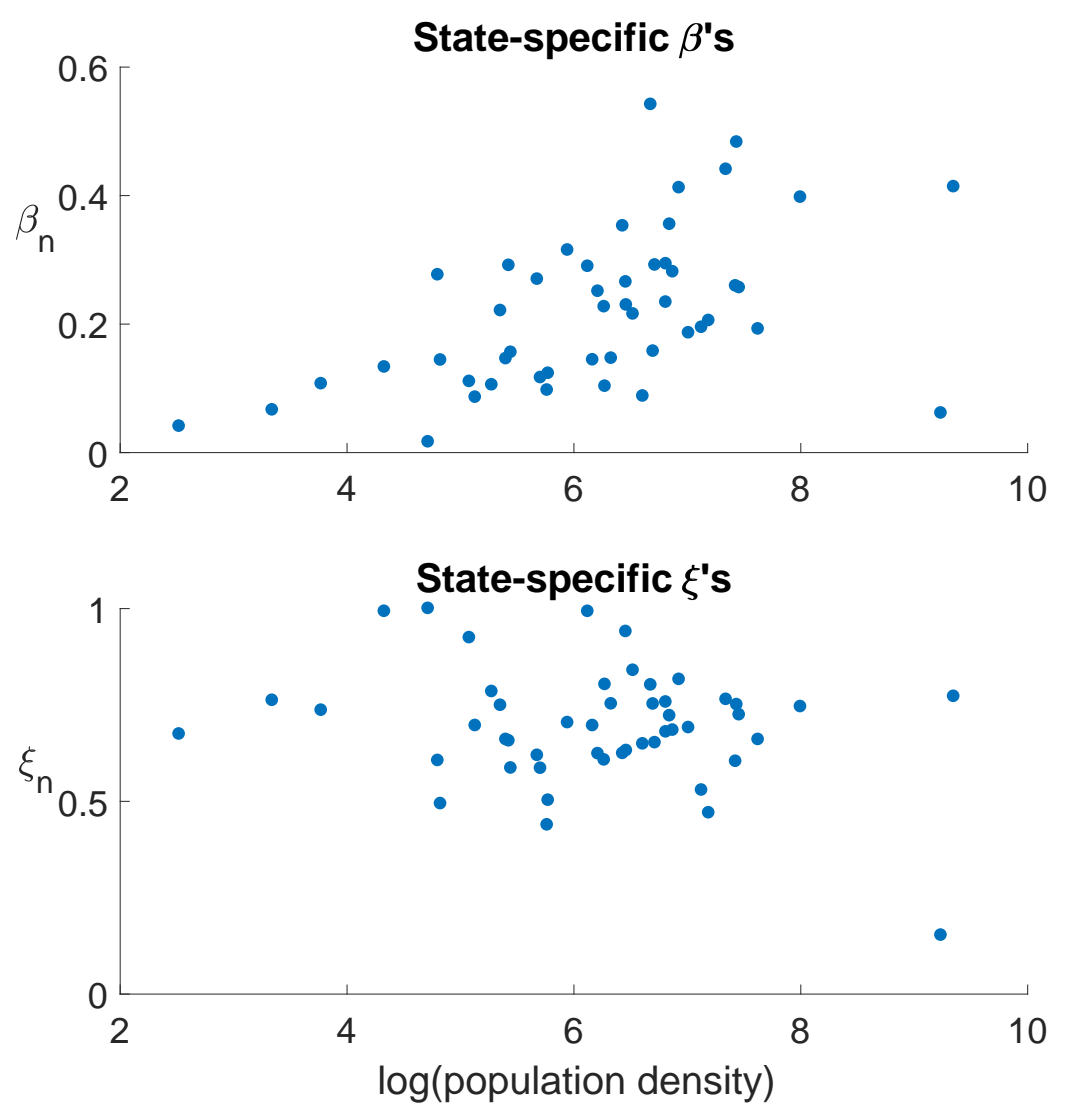
Figure 10: Model Fit - all confirmed cases

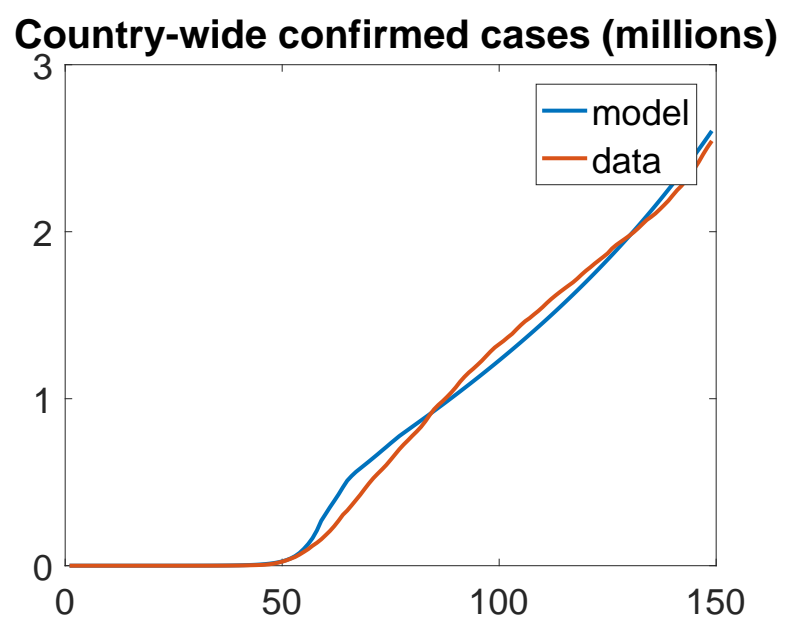

While it may not seem so, our model has relatively few free parameters (even with 49 statespecific values of $\beta$ and 48 state-specific values of $\xi$ ), because we have over 7,000 observations (49 regions over $150+$ days). Despite that, the model does a remarkably good job in replicating the data. Figure 10 plots the total number of confirmed cases observed in the data and generated by the model for the whole country. The time paths of confirmed cases per-capita for individual states and for DC are reported in the appendix. The $R^{2}$ between the cumulative infections for the whole country in model and in the data is 0.99 . For individual states, the model accounts for $98 \%$ of the overall variation in cumulative infections, for $97 \%$ of the variation within states, and $99 \%$ of the variation between states. Naturally, the model does a poorer job in accounting for the dynamics of the new infections. For the whole country, it accounts for the $73 \%$ of the variation in the data. For individual states, it accounts for $40 \%$ of the total variation, $30 \%$ of the variation within states, but for the $97 \%$ of the variation between states.

\subsection{Counter-factual simulations}

Given the overall good fit of the structural model, we proceed with using the model to perform two counterfactual simulations. In all counterfactual simulations, we use our benchmark parametriza- 
Table 4: Model Fit and Parameter Values

\begin{tabular}{|c|c|c|c|}
\hline Model specification & $\begin{array}{c}\beta_{n}=f\left(\text { density }_{n}\right) \\
\xi_{n}=1\end{array}$ & $\begin{array}{c}\beta_{n} \text { as fixed effects; } \\
\quad \xi_{n}=1\end{array}$ & $\begin{array}{c}\xi_{n} \text { and } \beta_{n} \\
\text { as fixed effects }\end{array}$ \\
\hline \multicolumn{4}{|l|}{ Parameters } \\
\hline$\rho$ & 0.144 & 0.094 & 0.167 \\
\hline$\kappa^{1}$ & 0.519 & 0.999 & 0.829 \\
\hline$\kappa^{2}$ & 0.519 & 0.997 & 0.477 \\
\hline$\kappa^{3}$ & 0.518 & 0.593 & 0.377 \\
\hline$\kappa^{4}$ & 0.322 & 0.359 & 0.114 \\
\hline$\kappa^{5}$ & 0.297 & 0.277 & 0.023 \\
\hline$b_{0}$ & -4.999 & n.a. & n.a. \\
\hline$b_{1}$ & 0.717 & n.a. & n.a. \\
\hline$b_{2}$ & -0.029 & n.a. & n.a. \\
\hline \multicolumn{4}{|l|}{ Model Fit - levels } \\
\hline country-wide & 0.984 & 0.987 & 0.993 \\
\hline states - total & 0.470 & 0.960 & 0.976 \\
\hline states - within & 0.545 & 0.947 & 0.970 \\
\hline states - between & 0.375 & 0.991 & 0.992 \\
\hline \multicolumn{4}{|c|}{ Model Fit - first differences } \\
\hline country-wide & 0.574 & 0.580 & 0.725 \\
\hline states - total & 0.131 & 0.301 & 0.395 \\
\hline states - within & 0.107 & 0.207 & 0.303 \\
\hline states - between & 0.291 & 0.919 & 0.968 \\
\hline
\end{tabular}

Notes: $f($ density $) \equiv b_{0}+b_{1} \log ($ density $)+b_{2} \log (\text { density })^{2}$. 
tion with state-specific values of $\beta_{n}$ and $\xi_{n}$. Naturally, any counterfactual simulation of a calibrated or estimated model that does not explicitly model people's behavior has to address the Lucas' critique (Lucas, 1976). We want to point out that to some extent we already capture the differences across states in behavioral response to restrictions by calibrating a state-specific parameter $\xi_{n}$. While it captures more than that, it partially mitigates those concerns. Ideally, we would have $\xi_{n}$ vary by the level of imposed restriction, but we are not able to identify that with current data. Given these considerations, our results should be interpreted as showing the impact of changes in restrictions under the assumption that compliance with them remains the same as it was before (i.e., not necessarily perfect).

Any counterfactual experiment is to some extent ad hoc. We present a few that we find the most interesting and informative. First, we investigate what would happen if states increased their maximum level of social distancing measures by 1 (of course, excluding the states where the max of the r-score variable equals 5). Second, we investigate what would happen if the states adopted their maximum level of social distancing 14 days earlier. Third, we investigate the role of the spillover parameter, by simulating the path of infections when its value is $25 \%$ lower. Finally, we combine the first with the last by simulating the impact of changing the restrictions in the environment where the spillover parameter is smaller (of course, using the simulated series from the third counterfactual as a benchmark).

The results of the counterfactual experiments are presented in Tables 5 and 6, and in Figures 11 through 14. In Figures 11-13 the first column indicates the impact on the whole country, the second column indicates the impact on the group of states where the counterfactual policy is implemented ("own effect"), and the third column indicates the impact on the group of remaining states ("spillover effect"). These two groups may be different for different counterfactuals, and in a few cases the second group is an empty set (so the spillover effect is not applicable). Tables 5 and 6 additionally separates these groups into two sub-columns - in each case the left subcolumn shows the simulated effect at the end of our data sample (June 28, 2020) and the right 
sub-column shows the simulated effect by December $31,2021 .{ }^{15}$ In all simulations we assume that social distancing measures which are in place on June 28, 2020, remain in place forever. One can interpret the difference between them as showing the short-term vs. the long-term effects. Table 5 shows percentage change, and Table 6 shows the change in the actual numbers of people.

Table 5: \% change in the number of confirmed cases (from the benchmark)

\begin{tabular}{|c|c|c|c|c|c|c|}
\hline \multirow[b]{2}{*}{ Counterfactual (states; action) } & \multicolumn{2}{|c|}{ country-wide } & \multicolumn{2}{|c|}{ own effect } & \multicolumn{2}{|c|}{ spillover } \\
\hline & $\begin{array}{l}\text { short- } \\
\text { run }\end{array}$ & $\begin{array}{l}\text { long- } \\
\text { run }\end{array}$ & $\begin{array}{l}\text { short- } \\
\text { run }\end{array}$ & $\begin{array}{l}\text { long- } \\
\text { run }\end{array}$ & $\begin{array}{l}\text { short- } \\
\text { run }\end{array}$ & $\begin{array}{c}\text { long- } \\
\text { run }\end{array}$ \\
\hline r-score $=2 ; \max$ add 1 & -0.19 & -0.26 & -36.33 & -32.46 & -0.03 & -0.04 \\
\hline r-score $=2 ;$ set $\max$ earlier & -0.16 & 0.00 & -25.21 & -0.07 & -0.04 & 0.00 \\
\hline $\mathrm{r}$-score $=3 ;$ max add 1 & -3.83 & -5.49 & -62.74 & -51.64 & -0.55 & -0.98 \\
\hline r-score $=3 ;$ set max earlier & -1.77 & 0.00 & -26.26 & -0.02 & -0.41 & 0.00 \\
\hline $\mathrm{r}$-score $=4 ; \max$ add 1 & -12.56 & -21.56 & -43.22 & -52.35 & -1.94 & -4.20 \\
\hline r-score $=4 ;$ set $\max$ earlier & -19.21 & -0.26 & -60.53 & -0.60 & -4.89 & -0.07 \\
\hline r-score $=2,3,4 ;$ max add 1 & -16.36 & -27.43 & -47.28 & -53.80 & -2.17 & -5.32 \\
\hline r-score $=2,3,4 ; \max$ add $1 ;(\rho \downarrow$ by $25 \%)$ & -13.03 & -28.26 & -44.29 & -55.64 & -1.11 & -5.03 \\
\hline $\mathrm{r}$-score $=5 ;$ max less 1 & 92.25 & 40.02 & 125.91 & 67.62 & 18.91 & 7.11 \\
\hline r-score $=5 ;$ set max earlier & -69.35 & -1.58 & -84.60 & -2.32 & -36.13 & -0.69 \\
\hline all; set max earlier & -85.32 & -1.89 & -85.32 & -1.89 & n.a. & n.a. \\
\hline all; set $\max$ on $3 / 19 / 2020$ & -36.76 & -0.55 & -36.76 & -0.55 & n.a. & n.a. \\
\hline all; $\rho \downarrow$ by $25 \%$ & -38.84 & -6.45 & -38.84 & -6.45 & n.a. & n.a. \\
\hline
\end{tabular}

Notes: On 3/19/2020 California was the first state that raised its social distancing measures to the level which corresponds to r-score $=5$. "set max earlier" means that the state sets the r-score to the state's specific maximum value 14 days earlier than in the data. "max add 1" means that when the state's r-score reaches the maximum value, we increase that maximum value by 1 (for states where $\max (\mathrm{r}$-score) $=5$ "max less $1 "$ means that when such state's r-score reaches maximum, it is set to 4). Short-run refers to simulated outcomes on $6 / 28 / 2020$. Long-run refers to simulated outcomes on $12 / 31 / 2021$. In the long-run simulations we assumed that restrictions in place on $6 / 28 / 2020$, remain in effect until the end of the simulation period.

Raising/lowering the max r-score by 1 The effects of increasing the maximum level of restrictions by 1 (or lowering it by 1 among states where $\max ($ r-score) $=5$ ) are shown in rows 1,3 , 5, 7-9 of Tables 5 and 6 . The first thing we notice is that the own effect is an order of magnitude larger than the spillover effect. Second, with the exception of the counterfactual in row 9 (most restrictive states reduce their restrictions by 1), the spillover effect in the long-run is stronger than

\footnotetext{
${ }^{15}$ Naturally, the long-term effects should be interpreted more cautiously.
} 
Figure 11: Changing restrictions in the more lax states $($ benchmark $=1$ )
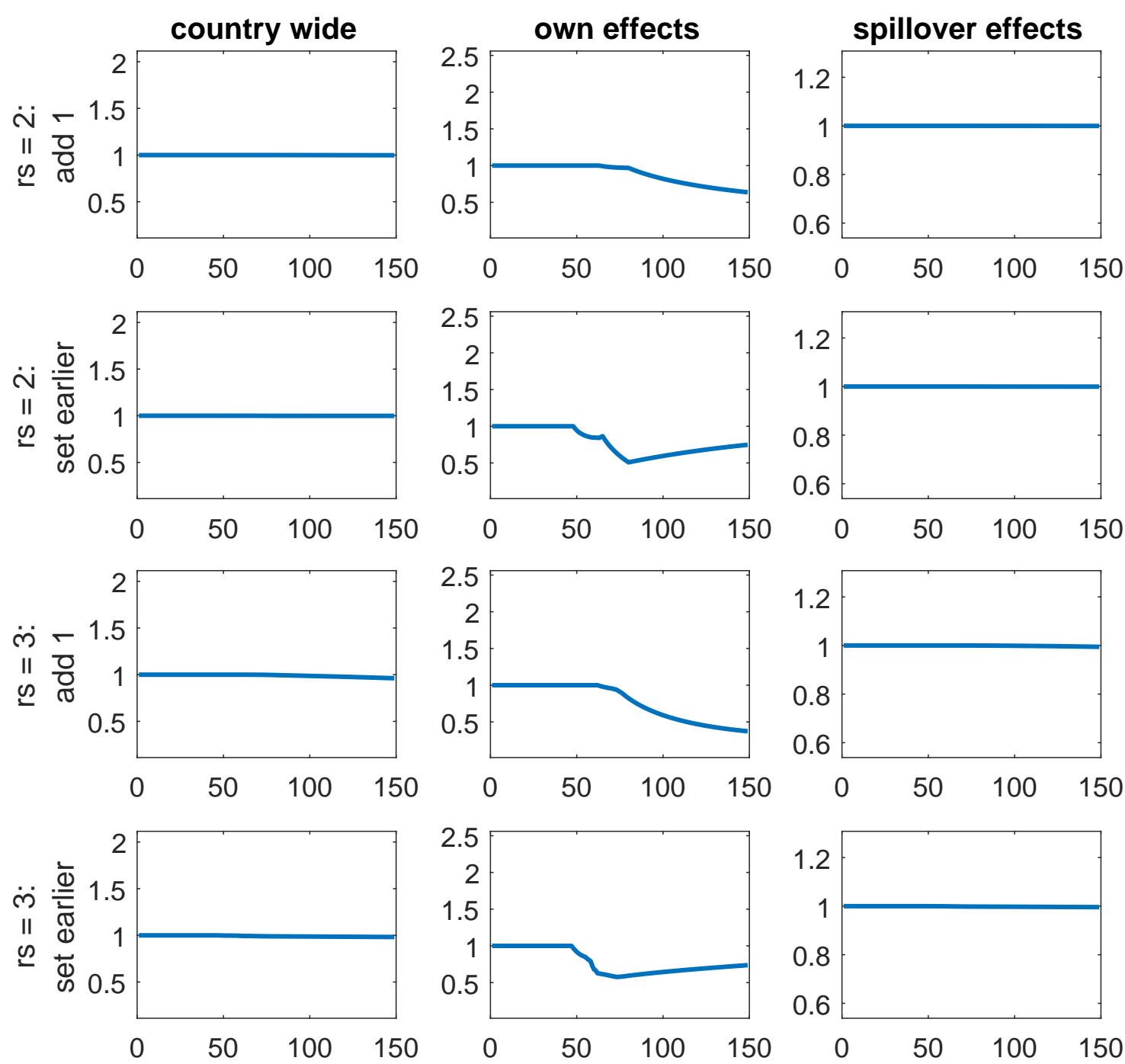
Figure 12: Changing restrictions in the more restrictive states $($ benchmark $=1$ )
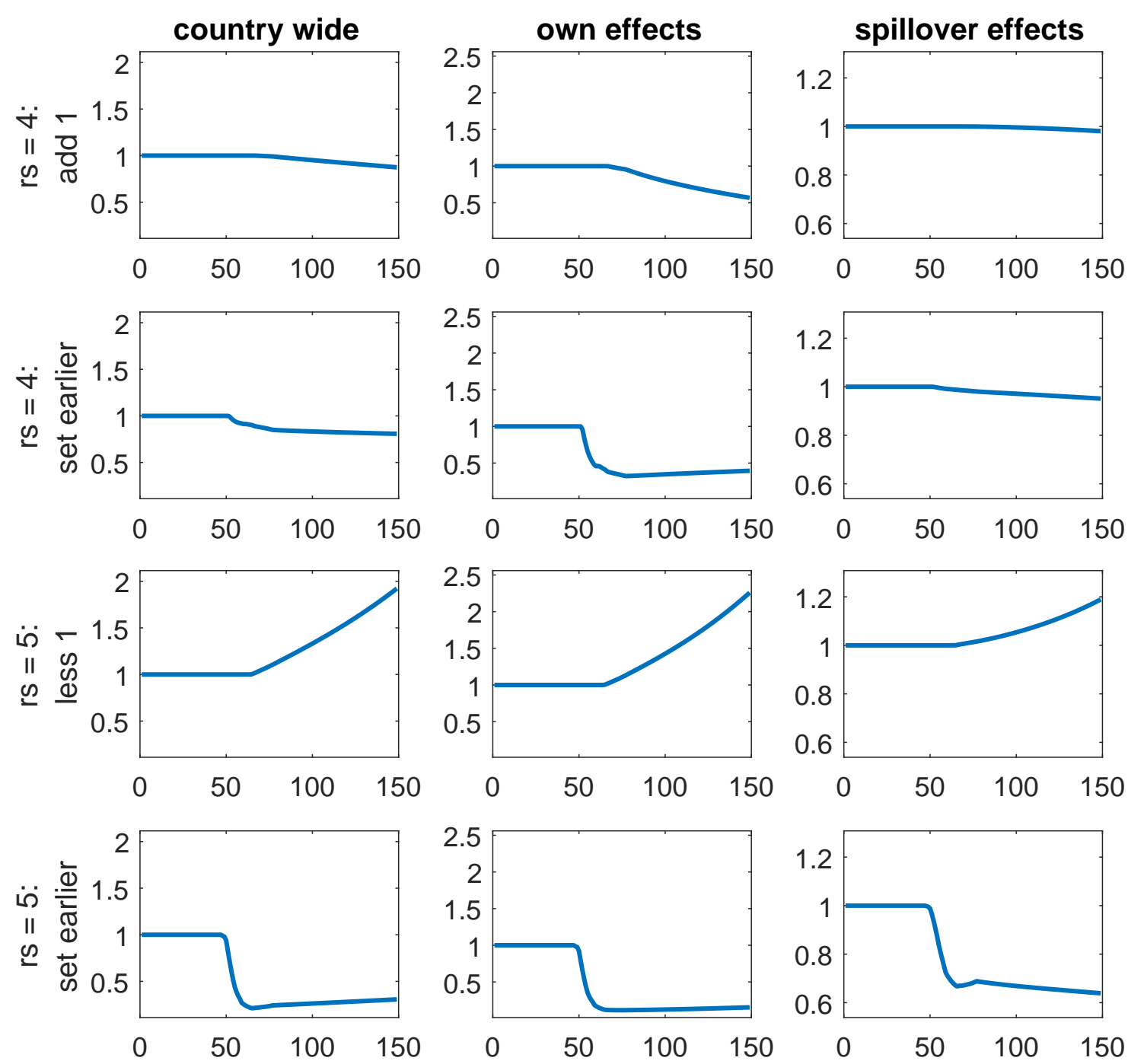
Figure 13: Changing restrictions in all but most restrictive states (benchmark $=1$ )
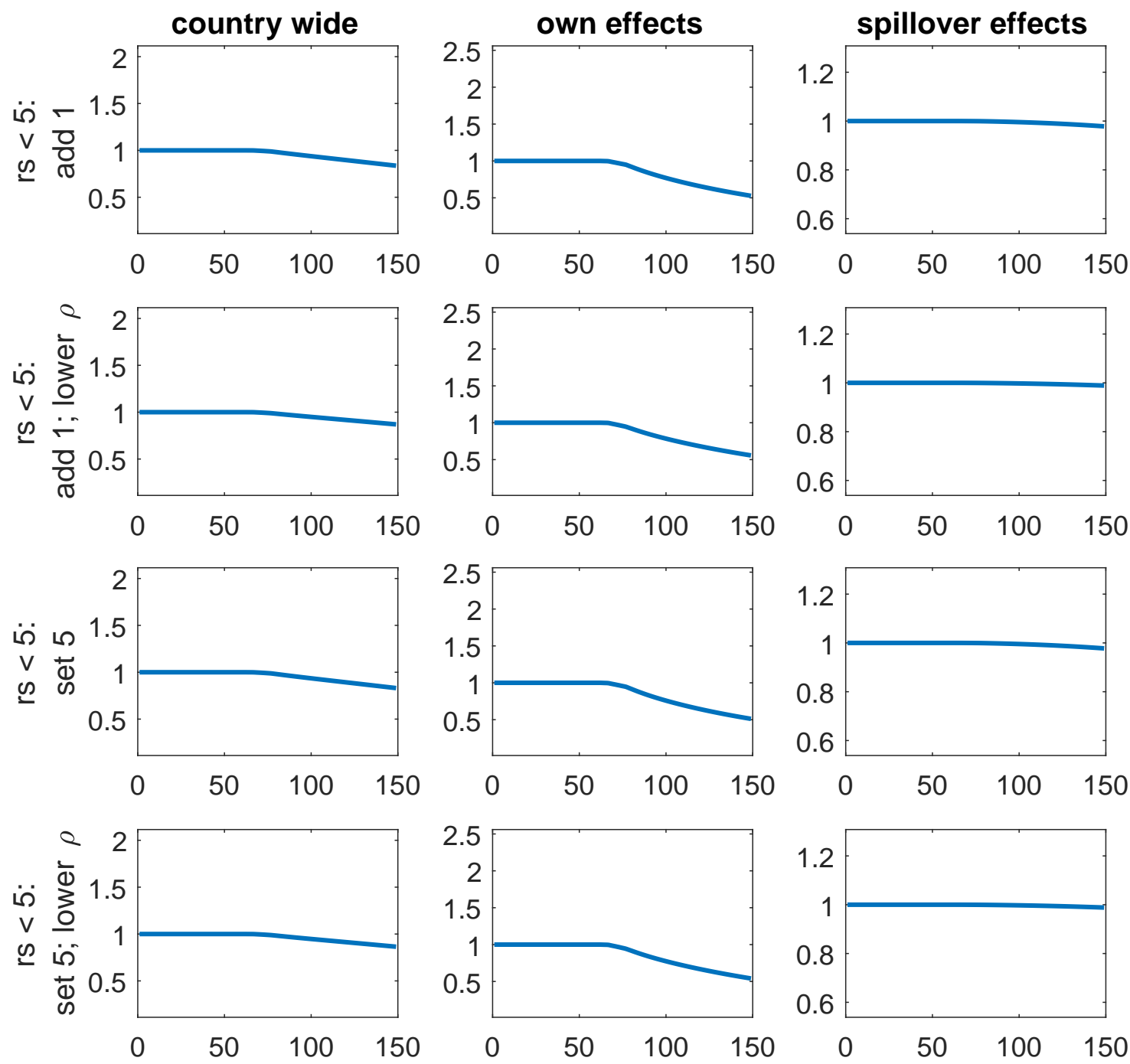
Figure 14: Lower spillovers, early restriction, and uniform timing (benchmark $=1$ )
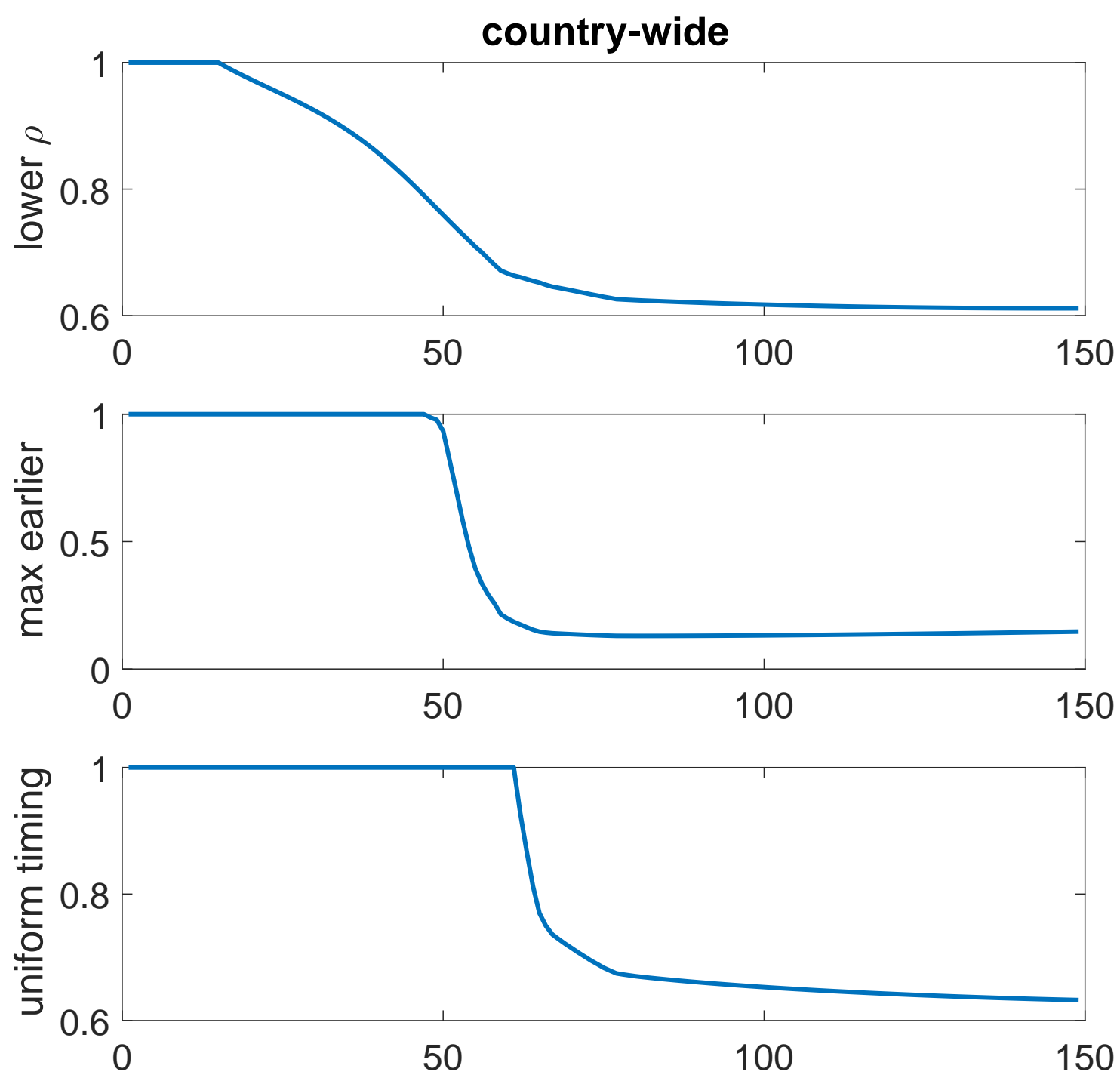
Table 6: change in the number of confirmed cases (from the benchmark) in thousands

\begin{tabular}{|c|c|c|c|c|c|c|}
\hline \multirow[b]{2}{*}{ Counterfactual (states; action) } & \multicolumn{2}{|c|}{ country-wide } & \multicolumn{2}{|c|}{ own effect } & \multicolumn{2}{|c|}{ spillover } \\
\hline & $\begin{array}{l}\text { short- } \\
\text { run }\end{array}$ & $\begin{array}{c}\text { long- } \\
\text { run }\end{array}$ & $\begin{array}{l}\text { short- } \\
\text { run }\end{array}$ & $\begin{array}{c}\text { long- } \\
\text { run }\end{array}$ & $\begin{array}{l}\text { short- } \\
\text { run }\end{array}$ & $\begin{array}{c}\text { long- } \\
\text { run }\end{array}$ \\
\hline $\mathrm{r}$-score $=2 ; \max$ add 1 & -5.1 & -369.8 & -4.4 & -307.7 & -0.7 & -62.2 \\
\hline r-score $=2 ;$ set max earlier & -4.0 & -0.9 & -3.0 & -0.7 & -1.0 & -0.2 \\
\hline $\mathrm{r}$-score $=3 ; \max$ add 1 & -99.6 & $-7,810.8$ & -86.0 & $-6,534.7$ & -13.7 & $-1,276.1$ \\
\hline r-score $=3 ;$ set $\max$ earlier & -46.0 & -4.8 & -36.0 & -3.1 & -10.0 & -1.6 \\
\hline $\mathrm{r}$-score $=4 ; \max$ add 1 & -327.0 & $-30,678.8$ & -289.5 & $-26,852.9$ & -37.5 & $-3,825.9$ \\
\hline r-score $=4 ;$ set max earlier & -500.1 & -373.6 & -405.5 & -307.5 & -94.6 & -66.2 \\
\hline $\mathrm{r}$-score $=2,3,4 ; \max$ add 1 & -425.9 & $-39,029.8$ & -387.2 & $-34,914.4$ & -38.7 & $-4,115.5$ \\
\hline $\mathrm{r}$-score $=2,3,4 ;$ max add $1 ;(\rho \downarrow$ by $25 \%)$ & -207.5 & $-37,609.2$ & -194.7 & $-33,983.2$ & -12.8 & $-3,626.0$ \\
\hline $\mathrm{r}$-score $=5 ; \max$ less 1 & $2,401.7$ & $56,940.0$ & $2,246.8$ & $52,325.5$ & 154.9 & $4,614.5$ \\
\hline r-score $=5 ;$ set max earlier & $-1,805.6$ & $-2,244.7$ & $-1,509.7$ & $-1,794.4$ & -295.9 & -450.3 \\
\hline all; set max earlier & $-2,221.3$ & $-2,688.1$ & $-2,221.3$ & $-2,688.1$ & n.a. & n.a. \\
\hline all; set $\max$ on $3 / 19 / 2020$ & -957.1 & -780.6 & -957.1 & -780.6 & n.a. & n.a. \\
\hline all; $\rho \downarrow$ by $25 \%$ & $-1,011.2$ & $-9,177.2$ & $-1,011.2$ & $-9,177.2$ & n.a. & n.a. \\
\hline
\end{tabular}

in the short-run. Third, even though the relative spillover effect is much smaller than the own effect, it can be quite sizeable. Among states where the $\max (\mathrm{r}$-score $)=4$, the spillover effect in the long-run is $-4.2 \%$, and the combined spillover effect among states with $\max$ (r-score) $<5$ is $-2.2 \%$ in the short-run and $-5.3 \%$ in the long-run (in this case, the spillover effect is the impact on states with $\max ($ r-score $)=5)$. While the percentages look small, as of $6 / 28 / 2020$, the total number of confirmed cases among states with $\max (\mathrm{r}$-score $)=5$ was $1.7 \mathrm{mln}$, so $2.2 \%$ corresponds to 37,000 people. The $-5.3 \%$ in the long-run corresponds to reducing the cumulative confirmed cases (in states other those that raise their restrictions) by 4 million towards the end of December $2021 .^{16}$ The short-term effects are depicted in Figures 11, 12, and 13.

Adopting max r-score earlier Similarly to changing the level of restrictions, earlier adoption of the maximum level of restrictions matters most when done by states for which the maximum r-score is 5 . The difference is that now the short-term effect is much stronger than the long-term effect. In the short-term, the own effect from early adoption for states with r-score $=5$ is $-84 \%$,

\footnotetext{
${ }^{16}$ Long-run simulations in all scenarios assume that states keep their maximum level of restrictions until the end of the simulation sample.
} 
and the spillover effect is $-36 \%$. In the long-term, those effects are drastically diminished, to $-2.3 \%$ and $-0.7 \%$, respectively. In other words, changing the timing of restrictions (without changing its ultimate maximum level), operates largely by flattening the infection curve rather than by reducing the total number of people that will eventually become infected. Among states that never reached the r-score of 5 , we observe a similar pattern, but its magnitude is smaller. The short-term effects are depicted in Figures 11 and 12, and in the second panel of Figure 14.

Lower spillover The effect of reducing the value of the spillover parameter is shown in the top panel of Figure 14 and in the bottom row of Tables 5 and 6. Not surprisingly, if spillovers across states' borders are smaller, the cumulative infections decline. Interestingly, the long-term effect is disproportionately smaller (see Tables 5 and 6). In other words, if U.S. states had the ability to restrict travel between them (akin to border closures between countries in the Schengen Zone), the main epidemiological benefit would operate through the flattening of the infection curve. ${ }^{17}$ The total number of confirmed cases in the long-run would still be smaller, but that decline would be nowhere near as large as the decline in the short-term. Finally, when the spillover parameter is smaller, the impact of changing the restrictions is diminished substantially in the short-run, but only marginally in the long-run (see Figure 13 and rows 7 and 8 in Tables 5 and 6).

Fragmented by policies, united by outcomes Finally, Table 7 shows how changing a policy within one group of states impacts that group as well as other groups. The key message from the table is quite clear - policy changes implemented by subsets of states have quantitatively significant effects on the rest of the country. In that sense, while a policy change may be local and uncoordinated, its impact is felt across the whole country.

\footnotetext{
${ }^{17}$ Eckardt et al. (2020) show that border closures between European regions significantly slowed down the spread of the virus.
} 
Table 7: Fraction of people infected by 12/31/2020 (median within subsets of states)

\begin{tabular}{lrrr}
\hline \hline & \multicolumn{3}{c}{ Subset of states } \\
\cline { 2 - 4 } & $\max (\mathrm{r}$-score $)=3$ & $\max (\mathrm{r}$-score $)=4$ & $\max (\mathrm{r}$-score $)=5$ \\
\hline benchmark & 0.61 & 0.38 & 0.33 \\
r-score $=3$ : add 1 & 0.49 & 0.31 & 0.26 \\
r-score $=4$ : add 1 & 0.42 & 0.17 & 0.28 \\
r-score $=5$ : less 1 & 0.65 & 0.53 & 0.60 \\
r-score $=2,3,4:$ add 1 & 0.30 & 0.12 & 0.22 \\
\hline \hline
\end{tabular}

\section{Conclusion}

In this paper we estimate the magnitude of inter-state diffusion of the Covid-19 infections. We find evidence that new cases diffuse across county lines, and that the spatial diffusion across counties is affected by the closure policies of adjacent states. Using a spatial version of the SIR model we find that tightening restrictions in states with the less restrictive policies could have reduced the infections in other states by more $2 \%$ in the first 3 months, and by more than $5 \%$ by the end of December 2021, corresponding to a reduction in the number of confirmed cases by 40,000 and 4 million, respectively.

The stylized picture of spatial diffusion provides consistent evidence of the effect of surrounding states' policies on a particular county's case load. The estimates from the spatial impulse response functions suggest that spatial correlation is significant for up to ten days (following a "shock" to new cases); while the estimates from traditional spatial models show the spatial correlation is significant between counties, and the r-score of counties in adjacent counties have a significant effect on the growth rate of a county's new cases.

The presence of inter-state spillovers significantly affected the rate of increase in the number of confirmed cases in the early stages of the outbreak. This result is important when we evaluate the "performance" of different regions in battling the pandemic. A unique feature of the United States is that its federal government cannot compel individual states to simply close their borders nor mandate state-specific lock-down policies. This only emphasizes the importance of other tools that 
promote coordination between states' authorities and regular citizens. First, uniform and consistent messaging on precautionary measures such as masks, or encouraging the compliance with social distancing restrictions and discouraging unnecessary inter-state travel are examples of such tools that would impact individual behavior. Second, the evidence provided in the literature thus far (Piguillem and Shi, 2020; Berger et al., 2020) suggests that there are potentially huge benefits from implementing a country-wide testing system - aimed at reducing the delay between test and result - thus revealing virus hot-spots much sooner to potential travelers. Finally, the literature on fiscal federalism may offer some insights into the role the federal government can play when the jurisdictional boundaries do not overlap with the boundaries of regions affected by local policies. ${ }^{18}$ Given that by the very nature of the problem any policy implemented or not implemented in response to a viral outbreak creates external effects on surrounding regions, we believe this is a very important area for further research.

\section{References}

Acemoglu, D., V. Chernozhukov, I. Werning, and M. D. Whinston (2020): "Optimal

Targeted Lockdowns in a Multi-Group SIR Model," Working Paper 27102, National Bureau of Economic Research.

Atkeson, A. (2020a): "How Deadly Is COVID-19? Understanding The Difficulties With Estimation Of Its Fatality Rate," Working Paper 26965, National Bureau of Economic Research.

- (2020b): "What Will Be the Economic Impact of COVID-19 in the US? Rough Estimates of Disease Scenarios," Working Paper 26867, National Bureau of Economic Research.

Atkeson, A., K. Kopecky, And T. Zha (2020): "Estimating and Forecasting Disease Scenarios for COVID-19 with an SIR Model," Working Paper 27335, National Bureau of Economic Research.

\footnotetext{
${ }^{18}$ See Oates (1999) for the literature review on that topic. Rothert (2020) discusses a few examples of federal fiscal tools that could impact local policies.
} 
Auerbach, A. J. And Y. Gorodnichenko (2012): "Measuring the output responses to fiscal policy," American Economic Journal: Economic Policy, 4, 1-27.

Beck, T. And W. Wagner (2020): "National containment policies and international cooperation," Covid Economics, 8, 120-134.

Berger, D. W., K. F. Herkenhoff, And S. Mongey (2020): “An SEIR Infectious Disease Model with Testing and Conditional Quarantine," Working Paper 26901, National Bureau of Economic Research.

Bisin, A. And A. Moro (2020): "Learning Epidemiology by Doing: The Empirical Implications of a Spatial-SIR Model with Behavioral Responses," Working Paper 27590, National Bureau of Economic Research.

BRADY, R. R. (2011): "Measuring the diffusion of housing prices across space and over time," Journal of Applied Econometrics, 26, 213-231.

- (2014): "The spatial diffusion of regional housing prices across US states," Regional Science and Urban Economics, 46, 150-166.

Briscese, G., N. Lacetera, M. Macis, and M. Tonin (2020): "Compliance with COVID-19 Social-Distancing Measures in Italy: The Role of Expectations and Duration," Working Paper 26916, National Bureau of Economic Research.

Cuñat, A. And R. Zymek (2020): "The (structural) gravity of epidemics," Covid Economics, 17.

Debarsy, N., C. Ertur, And J. P. LeSage (2012): "Interpreting dynamic space-time panel data models," Statistical Methodology, 9, 158-171.

Desmet, K. And R. Wacziarg (2020): "Understanding Spatial Variation in COVID-19 across the United States," Working Paper 27329, National Bureau of Economic Research. 
Dong, E., H. Du, And L. Gardner (2020): "An interactive web-based dashboard to track COVID-19 in real time," Lancet Infectious Diseases, 20, 533-534.

Eckardt, M., K. Kappner, And N. Wolf (2020): "Covid-19 across European Regions: the Role of Border Controls," Working Paper DP15178, Center for Economic and Policy Research.

Eichenbaum, M. S., S. Rebelo, and M. Trabandt (2020): "The Macroeconomics of Epidemics," Working Paper 26882, National Bureau of Economic Research.

Elhorst, J. (2014): "Spatial Panel Models [in:] Fisher, MM, Nijkamp, P.(eds.) Handbook of Regional Science," .

Elhorst, J. P. (2010): "Applied spatial econometrics: raising the bar," Spatial economic analysis, $5,9-28$.

(2012): "Dynamic spatial panels: models, methods, and inferences," Journal of geographical systems, 14, 5-28.

Ellison, G. (2020): "Implications of Heterogeneous SIR Models for Analyses of COVID-19," Working Paper 27373, National Bureau of Economic Research.

Favero, C. (2020): "Why is Covid-19 mortality in Lombardy so high? Evidence from the simulation of a SEIHCR model," Covid Economics, 4.

Fernández-Villaverde, J. And C. I. Jones (2020): "Estimating and Simulating a SIRD Model of COVID-19 for Many Countries, States, and Cities," Working Paper 27128, National Bureau of Economic Research.

Gerritse, M. (2020): "Cities and COVID-19 infections: population density, transmission speeds and sheltering responses," Covid Economics, 37.

Ginsburgh, V., G. Magerman, And I. Natali (2020): "COVID-19 and the Role of Economic 
Conditions in French Regional Departments," Working Papers ECARES 2020-17, ULB - Universite Libre de Bruxelles.

Glover, A., J. Heathcote, D. Krueger, And J.-V. Rios-Rull (2020): "Health versus Wealth: On the Distributional Effects of Controlling a Pandemic," Working Paper DP14606, Center for Economic and Policy Research.

Golgher, A. B. And P. R. Voss (2016): "How to interpret the coefficients of spatial models: Spillovers, direct and indirect effects," Spatial Demography, 4, 175-205.

Halleck Vega, S. And J. P. Elhorst (2015): "The SLX model," Journal of Regional Science, $55,339-363$.

Haug, A. A. And C. Smith (2012): "Local linear impulse responses for a small open economy," Oxford Bulletin of Economics and Statistics, 74, 470-492.

Holden, R. And D. Thornton (2020): "The Stochastic Reproduction Rate of a Virus," Covid Economics, 41.

Holly, S., M. H. Pesaran, and T. Yamagata (2011): "The spatial and temporal diffusion of house prices in the UK," Journal of Urban Economics, 69, 2-23.

Hornstein, A. (2020): "Social distancing, quarantine, contact tracing and testing: Implications of an augmented SEIR model," Covid Economics, 18.

Jinjarak, Y., R. Ahmed, S. Nair-Desai, W. Xin, and J. Aizenman (2020): “Accounting for Global COVID-19 Diffusion Patterns, January-April 2020," Working Paper 27185, National Bureau of Economic Research.

JoRDÀ, Ò. (2005): "Estimation and inference of impulse responses by local projections," American Economic Review, 95, 161-182. 
Jordì, Ò., M. Schularick, AND A. M. TAYlor (2016): "Sovereigns versus banks: credit, crises, and consequences," Journal of the European Economic Association, 14, 45-79.

— (2020): "The effects of quasi-random monetary experiments," Journal of Monetary Economics, 112, 22-40.

Kermack, W. O. And A. G. McKendrick (1927): "A contribution to the mathematical theory of epidemics," Proceedings of the royal society of london. Series A, Containing papers of a mathematical and physical character, 115, 700-721.

Kuchler, T., D. Russel, And J. Stroebel (2020): "The Geographic Spread of COVID-19 Correlates with the Structure of Social Networks as Measured by Facebook," Working Paper 26990, National Bureau of Economic Research.

Kuethe, T. H. And V. O. Pede (2011): "Regional housing price cycles: a spatio-temporal analysis using US state-level data," Regional studies, 45, 563-574.

LeSage, J. And R. Pace (2009): Introduction to Spatial Econometrics, Boca Raton: Taylor and Francis.

LuCAS, R. J. (1976): "Econometric policy evaluation: A critique," Carnegie-Rochester Conference Series on Public Policy, 1, 19-46.

McAdams, D. (2020): "Nash SIR: An economic-epidemiological model of strategic behaviour during a viral epidemic," Covid Economics, 16.

Michaud, A. And J. Rothert (2018): "Redistributive fiscal policies and business cycles in emerging economies," Journal of International Economics, 112, 123 - 133.

OAtes, W. E. (1999): "An Essay on Fiscal Federalism," Journal of Economic Literature, 37, 1120-1149. 
Pace, R. K., R. Barry, J. M. Clapp, and M. Rodriquez (1998): "Spatiotemporal autoregressive models of neighborhood effects," The Journal of Real Estate Finance and Economics, $17,15-33$.

Painter, M. And T. QIU (2020): "Political Beliefs affect Compliance with COVID-19 Social Distancing Orders," Covid Economics, 4.

Piguillem, F. And L. Shi (2020): "Optimal COVID-19 quarantine and testing policies," Covid Economics, 27.

Plagborg-Møller, M. And C. K. Wolf (2019): "Local projections and VARs estimate the same impulse responses," mimeo.

Pollakowski, H. O. AND T. S. Ray (1997): "Housing price diffusion patterns at different aggregation levels: an examination of housing market efficiency," Journal of Housing Research, $107-124$.

Pragyan Deb, Davide Furceri, J. D. O. and N. Tawk (2020): "The effect of containment measures on the COVID-19 pandemic," Covid Economics, 19.

Rana, G. A. And P. Shea (2015): "Estimating the causal relationship between foreclosures and unemployment during the great recession," Economics Letters, 134, 90-93.

Rothert, J. (2020): "Optimal federal redistribution during the uncoordinated response to a pandemic," Departmental working papers, United States Naval Academy Department of Economics.

Simonov, A., S. K. Sacher, J.-P. H. Dubé, And S. Biswas (2020): "The Persuasive Effect of Fox News: Non-Compliance with Social Distancing During the Covid-19 Pandemic," Working Paper 27237, National Bureau of Economic Research.

Verwimp, P. (2020): "The Spread of COVID-19 in Belgium: a Municipality-Level Analysis," Working Papers ECARES 2020-25, ULB - Universite Libre de Bruxelles. 
WeBer, E. (2020): "Which measures flattened the curve in Germany?" Covid Economics, 24. 


\section{A States' summary statistics and calibrated fixed effects}

\begin{tabular}{|c|c|c|c|c|c|c|}
\hline State & $\boldsymbol{\beta}_{n}$ & $\xi_{n}$ & Density & Cases per $1 \mathrm{mln}$ & $\max (r$-score $)$ & GOP vote \\
\hline $\mathrm{AL}$ & 0.29 & 0.66 & 227.8 & 7250.8 & 5 & 0.63 \\
\hline $\mathrm{AR}$ & 0.09 & 0.70 & 169.4 & 6339.5 & 3 & 0.61 \\
\hline $\mathrm{AZ}$ & 0.10 & 0.44 & 319.3 & 10313.0 & 3 & 0.50 \\
\hline $\mathrm{CA}$ & 0.21 & 0.47 & 1326.5 & 5484.6 & 5 & 0.34 \\
\hline $\mathrm{CO}$ & 0.29 & 0.68 & 909.7 & 5739.1 & 5 & 0.44 \\
\hline $\mathrm{CT}$ & 0.23 & 0.76 & 908.9 & 12890.1 & 4 & 0.41 \\
\hline $\mathrm{DC}$ & 0.06 & 0.15 & 10275.8 & 14588.8 & 5 & 0.04 \\
\hline $\mathrm{DE}$ & 0.09 & 0.65 & 742.1 & 11576.0 & 5 & 0.42 \\
\hline FL & 0.54 & 0.80 & 795.9 & 6616.4 & 4 & 0.48 \\
\hline GA & 0.41 & 0.82 & 1021.6 & 6694.3 & 4 & 0.51 \\
\hline IA & 0.16 & 0.59 & 231.8 & 9034.4 & 4 & 0.52 \\
\hline ID & 0.11 & 0.78 & 196.0 & 3049.8 & 5 & 0.60 \\
\hline IL & 0.26 & 0.60 & 1681.7 & 11150.1 & 5 & 0.38 \\
\hline IN & 0.23 & 0.63 & 641.7 & 6884.6 & 5 & 0.57 \\
\hline $\mathrm{KS}$ & 0.29 & 0.99 & 456.7 & 4814.0 & 3 & 0.57 \\
\hline KY & 0.15 & 0.75 & 561.7 & 3464.3 & 4 & 0.63 \\
\hline LA & 0.31 & 0.70 & 382.4 & 12065.5 & 5 & 0.58 \\
\hline MA & 0.26 & 0.72 & 1735.3 & 15702.4 & 4 & 0.33 \\
\hline MD & 0.48 & 0.75 & 1698.8 & 11147.3 & 5 & 0.34 \\
\hline $\mathrm{ME}$ & 0.28 & 0.61 & 121.8 & 2380.4 & 5 & 0.45 \\
\hline MI & 0.36 & 0.72 & 940.1 & 6991.2 & 5 & 0.47 \\
\hline $\mathrm{MN}$ & 0.28 & 0.68 & 966.2 & 6320.8 & 4 & 0.45 \\
\hline MO & 0.16 & 0.75 & 812.6 & 3450.8 & 4 & 0.57 \\
\hline
\end{tabular}




\begin{tabular}{|c|c|c|c|c|c|c|}
\hline State & $\boldsymbol{\beta}_{n}$ & $\xi_{n}$ & Density & Cases per $1 \mathrm{mln}$ & $\max (r$-score $)$ & GOP vote \\
\hline MS & 0.14 & 0.49 & 124.7 & 8671.9 & 5 & 0.59 \\
\hline MT & 0.07 & 0.76 & 28.3 & 812.4 & 5 & 0.56 \\
\hline $\mathrm{NC}$ & 0.35 & 0.62 & 621.6 & 5988.1 & 5 & 0.51 \\
\hline ND & 0.11 & 0.74 & 43.6 & 4598.2 & 2 & 0.64 \\
\hline $\mathrm{NE}$ & 0.27 & 0.94 & 639.1 & 9796.5 & 3 & 0.59 \\
\hline $\mathrm{NH}$ & 0.12 & 0.59 & 301.1 & 4235.3 & 5 & 0.47 \\
\hline NJ & 0.40 & 0.75 & 2978.5 & 19350.6 & 5 & 0.40 \\
\hline NM & 0.22 & 0.75 & 211.6 & 5635.6 & 4 & 0.42 \\
\hline NV & 0.15 & 0.66 & 222.0 & 5664.1 & 5 & 0.45 \\
\hline NY & 0.41 & 0.77 & 11497.0 & 20330.0 & 5 & 0.35 \\
\hline $\mathrm{OH}$ & 0.29 & 0.65 & 825.9 & 4303.8 & 5 & 0.52 \\
\hline OK & 0.14 & 0.70 & 476.9 & 3282.7 & 4 & 0.65 \\
\hline OR & 0.10 & 0.80 & 531.6 & 1992.0 & 4 & 0.41 \\
\hline PA & 0.19 & 0.66 & 2050.2 & 7010.6 & 5 & 0.49 \\
\hline RI & 0.19 & 0.69 & 1110.4 & 14134.9 & 4 & 0.40 \\
\hline $\mathrm{SC}$ & 0.27 & 0.62 & 292.8 & 6553.7 & 4 & 0.55 \\
\hline $\mathrm{SD}$ & 0.13 & 0.99 & 76.0 & 7697.7 & 2 & 0.61 \\
\hline $\mathrm{TN}$ & 0.23 & 0.61 & 527.9 & 5900.3 & 5 & 0.61 \\
\hline $\mathrm{TX}$ & 0.19 & 0.53 & 1245.4 & 5306.1 & 4 & 0.51 \\
\hline UT & 0.22 & 0.84 & 680.8 & 6692.3 & 3 & 0.46 \\
\hline VA & 0.44 & 0.76 & 1545.9 & 7560.2 & 5 & 0.45 \\
\hline VT & 0.02 & 1.00 & 111.8 & 1909.6 & 5 & 0.33 \\
\hline WA & 0.25 & 0.62 & 499.7 & 4424.5 & 5 & 0.39 \\
\hline WI & 0.12 & 0.50 & 322.2 & 4791.7 & 5 & 0.48 \\
\hline
\end{tabular}

Continued on next page 


\begin{tabular}{lllrrrr} 
State & $\boldsymbol{\beta}_{\boldsymbol{n}}$ & $\boldsymbol{\xi}_{\boldsymbol{n}}$ & Density & Cases per $\mathbf{1} \mathbf{~ m l n}$ & $\max (\mathbf{r}-$ score $)$ & GOP vote \\
\hline WV & 0.11 & 0.92 & 160.8 & 1568.3 & 5 & 0.69 \\
WY & 0.04 & 0.67 & 12.4 & 2452.7 & 3 & 0.70 \\
& & & & & \\
\hline \hline
\end{tabular}




\section{B SIR model}

This appendix shows the model fit for individual 49 contiguous regions ( 48 states + DC) from the benchmark calibration of the model described in Section 4 .
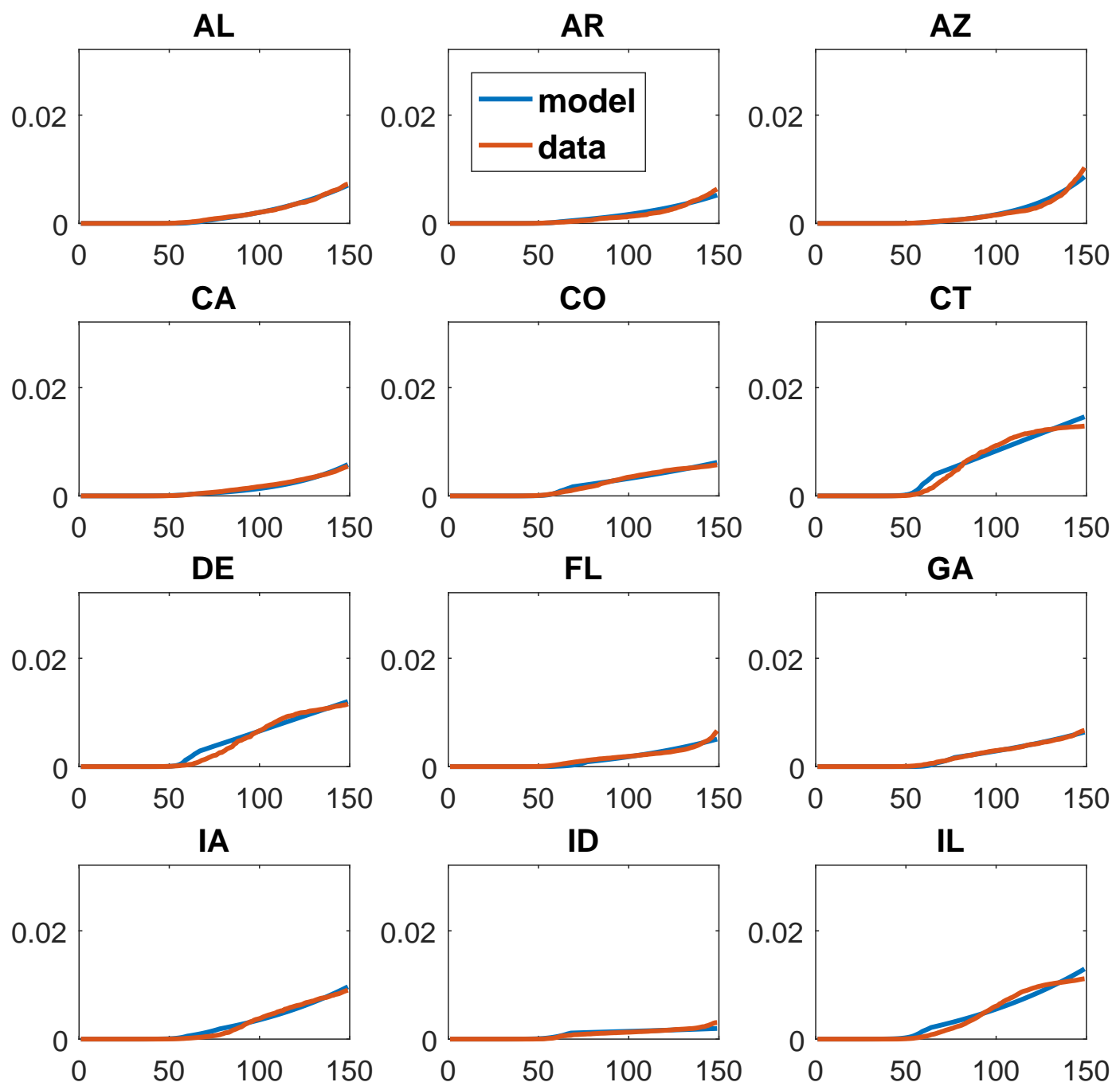

Figure 15: Model (blue) vs. data (red) - individual states 

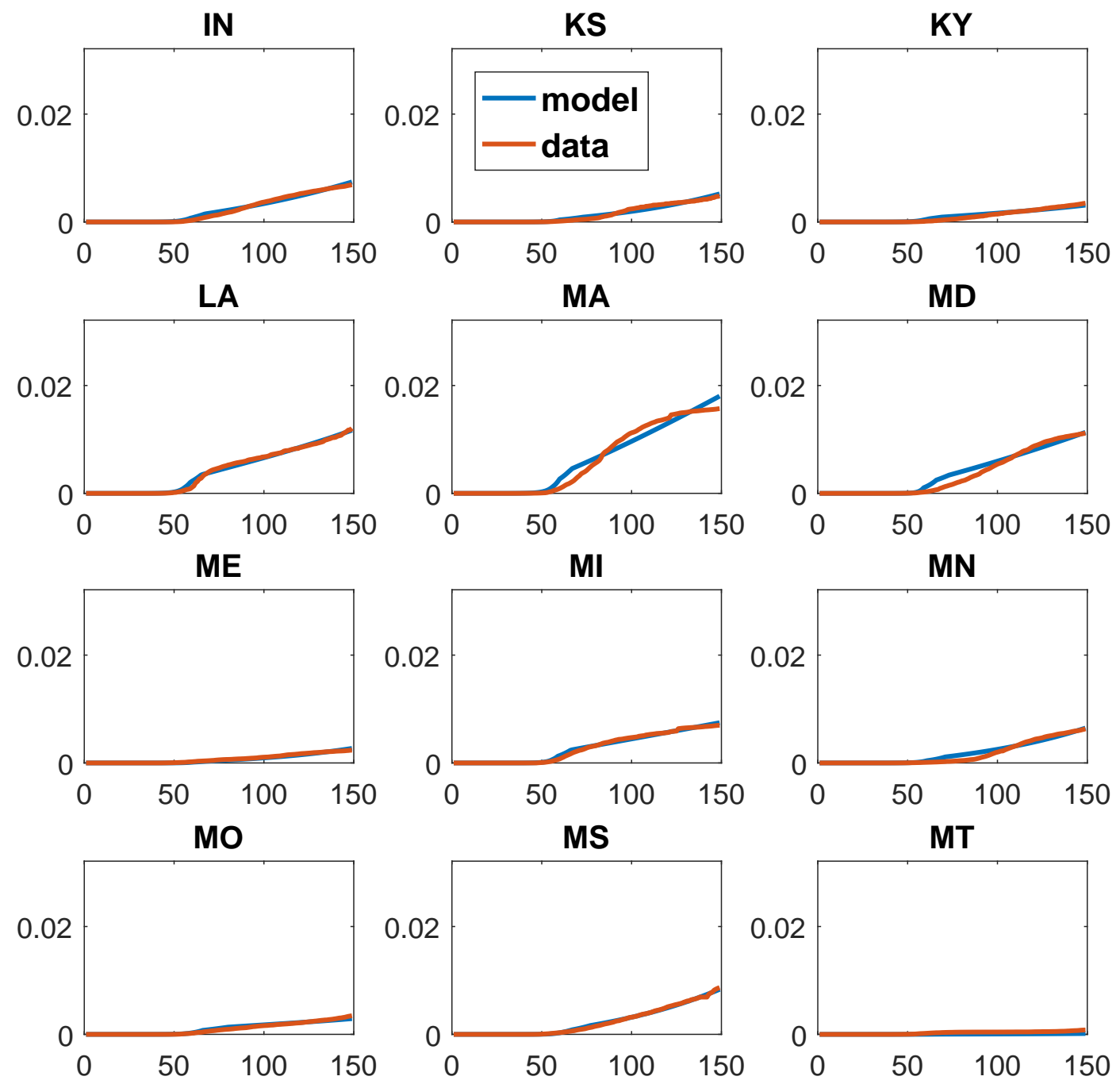

Figure 16: Model (blue) vs. data (red) - individual states 

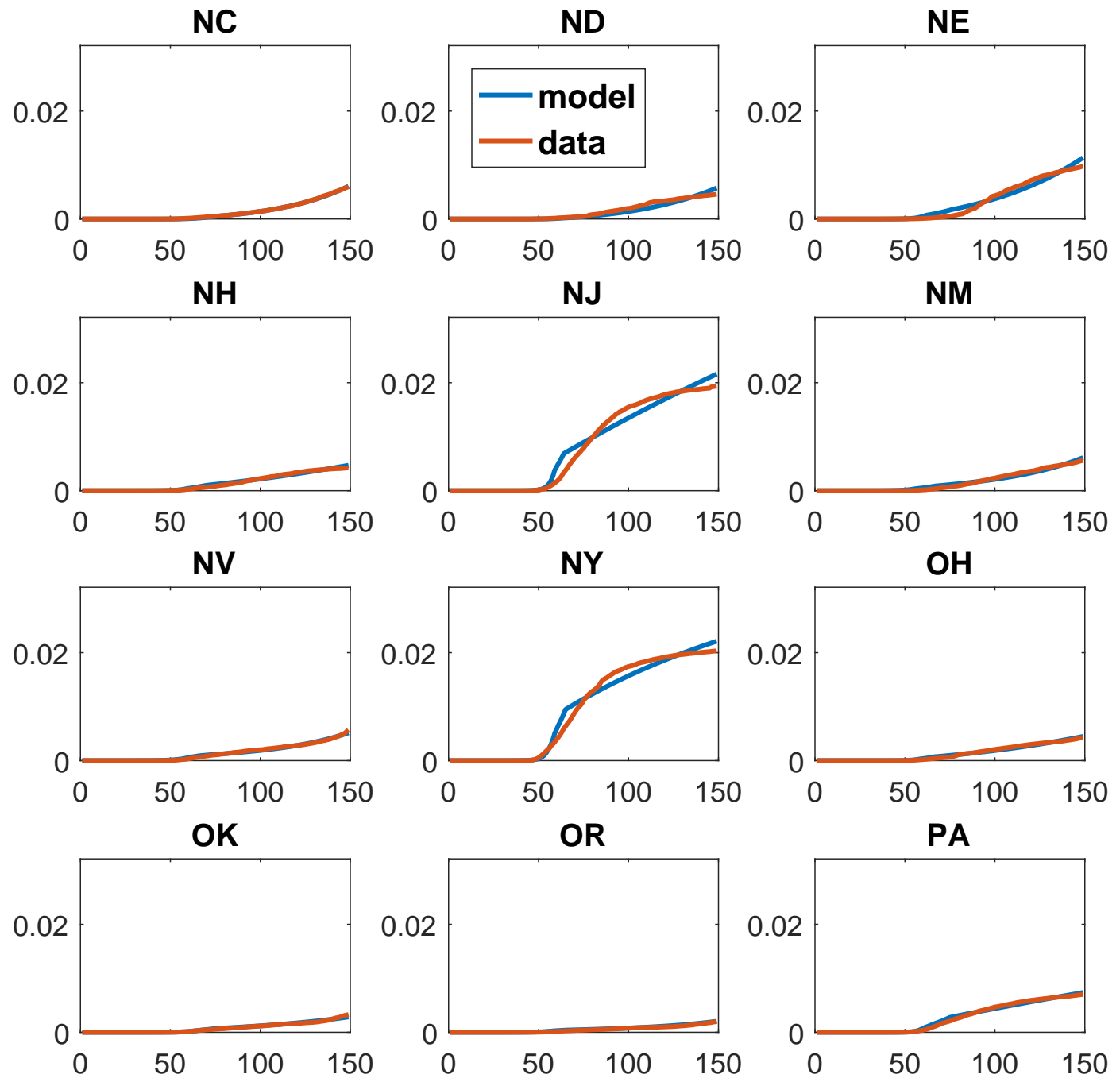

Figure 17: Model (blue) vs. data (red) - individual states 

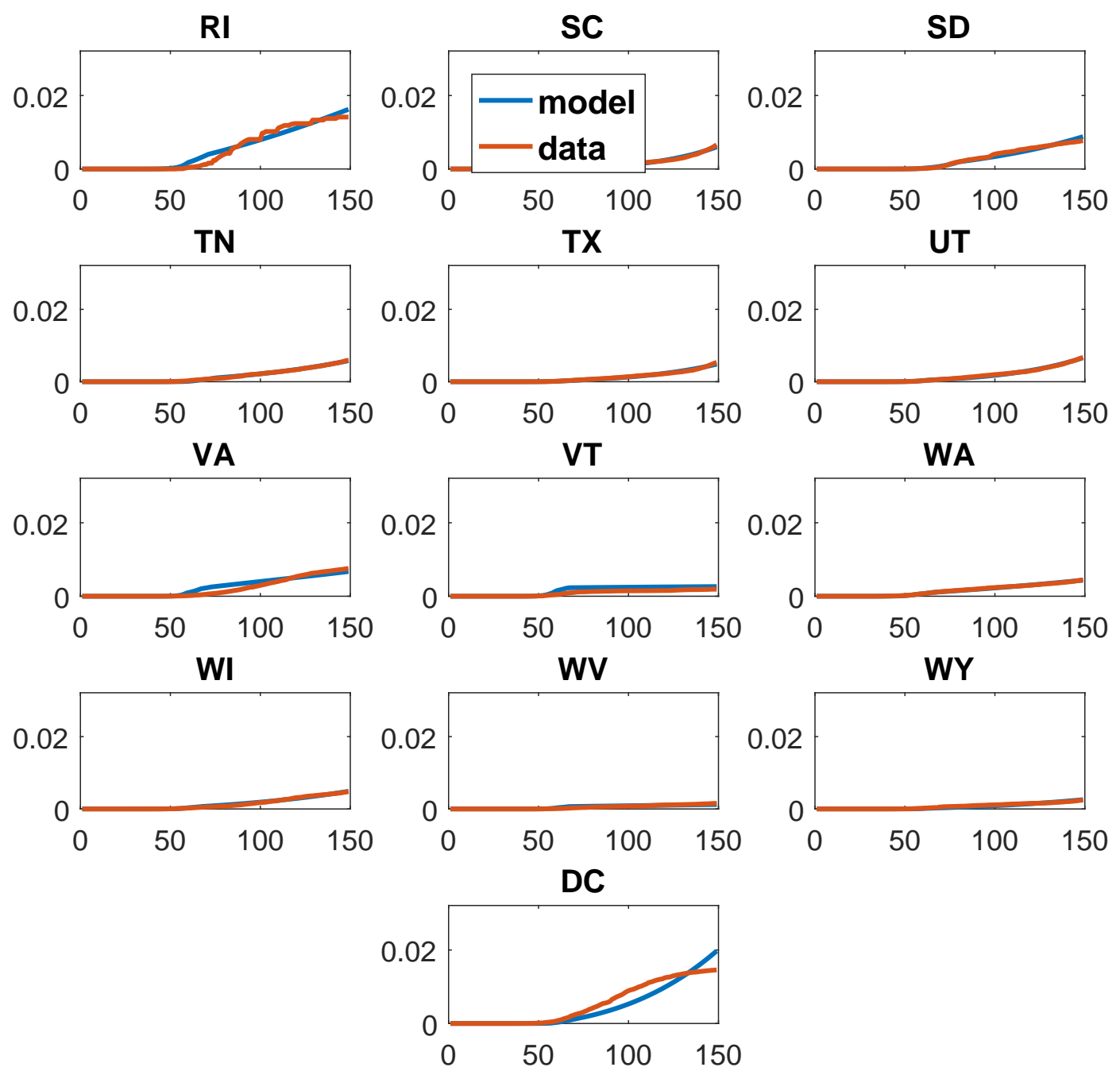

Figure 18: Model (blue) vs. data (red) - individual states 